\title{
PPAR- $\gamma$ Agonists and Their Effects on IGF-I Receptor Signaling: Implications for Cancer
}

\author{
A. Belfiore, ${ }^{1}$ M. Genua, ${ }^{2}$ and R. Malaguarnera ${ }^{1}$ \\ ${ }^{1}$ Endocrinology Unit, Department of Clinical and Experimental Medicine, University of Catanzaro, 88100 Catanzaro, Italy \\ ${ }^{2}$ Endocrinology Unit, Department of Internal and Specialistic Medicine, Garibaldi-Nesima Hospital, University of Catania, \\ 95122 Catania, Italy
}

Correspondence should be addressed to A. Belfiore, belfiore@unicz.it

Received 8 February 2009; Accepted 4 May 2009

Recommended by Antonio Brunetti

It is now well established that the development and progression of a variety of human malignancies are associated with dysregulated activity of the insulin-like growth factor (IGF) system. In this regard, promising drugs have been developed to target the IGF-I receptor or its ligands. These therapies are limited by the development of insulin resistance and compensatory hyperinsulinemia, which in turn, may stimulate cancer growth. Novel therapeutic approaches are, therefore, required. Synthetic PPAR- $\gamma$ agonists, such as thiazolidinediones (TZDs), are drugs universally used as antidiabetic agents in patients with type 2 diabetes. In addition of acting as insulin sensitizers, PPAR- $\gamma$ agonists mediate in vitro and in vivo pleiotropic anticancer effects. At least some of these effects appear to be linked with the downregulation of the IGF system, which is induced by the cross-talk of PPAR- $\gamma$ agonists with multiple components of the IGF system signaling. As hyperinsulinemia is an emerging cancer risk factor, the insulin lowering action of PPAR- $\gamma$ agonists may be expected to be also beneficial to reduce cancer development and/or progression. In light of these evidences, TZDs or other PPAR- $\gamma$ agonists may be exploited in those tumors "addicted" to the IGF signaling and/or in tumors occurring in hyperinsulinemic patients.

Copyright (C) 2009 A. Belfiore et al. This is an open access article distributed under the Creative Commons Attribution License, which permits unrestricted use, distribution, and reproduction in any medium, provided the original work is properly cited.

\section{Introduction}

Traditional anticancer therapies as chemotherapy and radiations are often unable to eradicate advanced cancers. Novel therapeutic modalities are, therefore, needed in the aim to lower the threshold for cancer cell death induced by traditional therapies.

The insulin-like growth factor (IGF) system has recently emerged as having a relevant role in cancer development and progression and in the resistance to drug-induced apoptosis. It is now well established that the IGF system is dysregulated/overactivated in a variety of human malignancies. Common mechanisms of dysregulation include autocrine and/or paracrine secretion of insulin-like growth factors (IGF-I and IGF-II) and overexpression of their cognate receptors (the IGF-I receptor, IGF-IR, and the closely related insulin receptor, IR). One viable anticancer strategy is, therefore, to target the various IGF system components that are dysregulated and that sustain increased constitutive IGFs' signaling in cancer cells.
Most anticancer strategies designed to curtail the IGF system dysregulation have been designed to target the IGF-IR [1-3]. In this regard, promising drugs have been developed, as small molecules with specific IGF-IR tyrosine kinase inhibiting activity and antiIGF-IR monoclonal antibodies that cause ligand binding inhibition and receptor downregulation and degradation. Other approaches have chosen IGFI and/or IGF-II as targets. Some of these compounds have shown promising activity in preclinical studies and are now being evaluated in phase I and phase II clinical trials. The aberrant expression of the insulin receptor isoform A (IRA) in malignant cells has also been advocated as a target. One limit of all these targeted therapies is the occurrence of insulin resistance and compensatory hyperinsulinemia caused by either direct impairment of the IR function or by growth hormone $(\mathrm{GH})$ increase in response to the reduced IGFs signaling $[4,5]$.

Unfortunately, several epidemiological studies have shown that a high level of circulating insulin (hyperinsulinemia) is associated with an increased risk for a number 
of malignancies [6]. Moreover, hyperinsulinemia is very common in western societies because closely associated with obesity and type 2 diabetes $[4,7,8]$.

Thiazolidinediones (TZDs) are synthetic PPARs agonists that are widely used as antidiabetic agents in patients with type 2 diabetes. These drugs ameliorate tissue sensitivity to insulin and, indirectly, cause a reduction of circulating insulin levels. Moreover, TZDs, as other PPAR- $\gamma$ agonists, such as the prostanoid 15d-PGJ2 [9], induce a variety of favorable changes (growth arrest, apoptosis, and/or partial redifferentiation) in several malignancies, including liposarcoma, and cancers of the breast, colon, pancreas, and prostate [10-18].

We will herein review the available evidences indicating that these anticancer effects of PPAR- $\gamma$ agonists are partially related to the downregulation of the IGF system activity at various levels. On the basis of these evidences, we suggest that TZDs or other PPAR- $\gamma$ agonists may be a useful adjunct to the therapy of IGFs-driven malignancies.

\section{The IGF System and Its Role in Cancer}

2.1. Components of the IGF System. The IGF system is composed by at least two closed related receptors, three ligands (insulin and insulin-like growth factors I and II) and six ligand-binding proteins (IGF-BPs) (Figure 1(a)) [19, 20]. The two receptors, the type I IGF receptor (IGF-IR) and the insulin receptor (IR) are tetrameric glycoproteins composed of two extracellular $\alpha$ - and two transmembrane $\beta$-subunits linked by disulfide bonds [21, 22]. The $\alpha$ subunits contain the ligand binding site while the $\beta$-subunits contain a tyrosine kinase domain. These two receptors share more than 50\% overall amino acid sequence homology and $84 \%$ homology in the tyrosine kinase domains. The transmembrane domain has a crucial role in recruiting intracellular mediators [23] through two conserved tyrosine residues.

The IR exists in two isoforms that differ for the inclusion (isoform B or IR-B) or the exclusion (isoform A or IR-A) of 12 aminoacid residues encoded by exon 11 [24, 25]. These two IR isoforms appear to have different ligand specificity and tissue distribution [26-29].

Because of the high sequence similarity between the IR and the IGF-IR [21, 22], an IR hemireceptor may assemble not only with a second IR hemireceptor but also with an IGFIR hemireceptor, forming a hybrid IR/IGF-IR receptor (HR).

The signaling of these receptors regulates crucial functions of multicellular organisms, such as glucose metabolism and growth and life span in response to nutrients $[30,31]$.

IGF-I and IGF-II expressions were first analyzed in rodents where IGF-II gene is widespread expressed in prenatal period and diminishes dramatically after birth. In contrast, IGF-I levels are low during the prenatal period and increase significantly during puberty and adulthood. The overall picture of IGFs expression in rodents initially led to the associate IGF-II as a fetal growth factor and IGF-I as an adult growth factor. However, this expression pattern is not observed in humans, as both IGF-I and IGF-II are produced in human tissue during lifetime period.
The human IGF-I gene is located on chromosome 12 and has two promoter sites [20]. Mature IGF-I is a $7.7 \mathrm{kDa}$ protein that has $62 \%$ homology with IGF-II in its amino acid sequence [20]. The human IGF-II is encoded by a 9-exons gene located on chromosome 11p15. Multiple transcripts are synthesized as a result of alternate promoter usage [32]. Promoter 1 is active only in adult liver, while $\mathrm{P} 2-4$ promoters are active in most fetal tissues. Activation of P3 and P4 promoters is common in cancer cells [33].

The biological activity of the IGF ligands is also modulated by a family of high-affinity IGF binding proteins (IGFBP 1-6). IGFBP-3 is the predominant binding protein expressed in serum, and most circulating IGF-I and IGF-II are bound in a ternary complex with IGFBP-3 and a third component, the acid-labile subunit (ALS). The IGFBPs rule IGF action by increasing the half-lives of circulating IGFs, by controlling their availability for receptor binding. IGFBPs-14 have similar affinities for IGF-I and IGF-II whereas IGFBP5 and 6 bind IGF-II with a 10- and 100-fold higher affinity, respectively, than IGF-I [34-36].

A detailed description of the different components of the IGF system and of the complex signaling network activated by ligand binding to the IGF-IR and the IR is beyond the scope of this article and can be found elsewhere [37]. We will herein provide a brief overview of the major signaling pathways common to both receptors in order to describe the consequences of the IGF system dysregulation frequently observed in cancer and the way PPAR- $\gamma$ agonists may affect these pathways.

2.2. The IGF System Signaling Pathways. Both IGF-I and insulin bind to the extracellular $\alpha$-subunit of their cognate receptor and induce a conformational change that causes the activation of the receptor tyrosine-kinase and the autophosphorylation of tyrosine residues of the intracellular $\beta$-subunit at the level of the catalytic domain, the juxtamembrane domain and the C-terminus [38]. Tyrosine phosphorylation causes the recruitment of several intracellular substrates which function as either docking proteins (IRS1, IRS-2) or adaptors (SHC, Grb2) for other intracellular proteins that have specific recognition domains, termed Srchomology-2 (SH2) domains [39]. In turn these substrates bind and recruit other intracellular proteins (Figure 1(b)) [40].

IRS-1, which binds to phosphotyrosine residues in the juxtamembrane domain with its Phosphotyrosine Binding (PTB) domain, has 20-22 potential tyrosine phosphorylation sites surrounded by possible binding sites for SH2proteins [39]. Among the relevant $\mathrm{SH} 2$ domain-containing proteins, the phosphatidylinositol-3 kinase (PI3K) [41] and the GTPase activating protein (GAP) of Ras [42] originate the two major signaling pathways, common to both the IR and the IGF-IR.

The PI3K binds to IRS proteins through its regulatory subunit (p85), which then recruits the PI3K catalytic subunit (p110) to the plasma membrane, where it phosphorylates phosphatidylinositol-(4,5)-bisphospate (PIP2) to phosphatidylinositol-(3,4,5)-trisphosphate (PIP3). PIP3, in turn, recruits the protein kinase Akt and allows its activation 


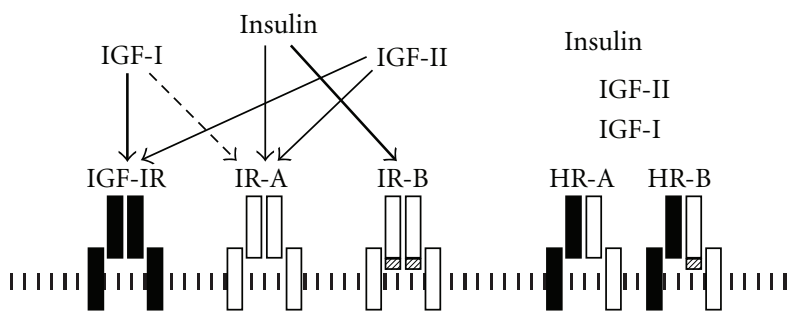

(a)

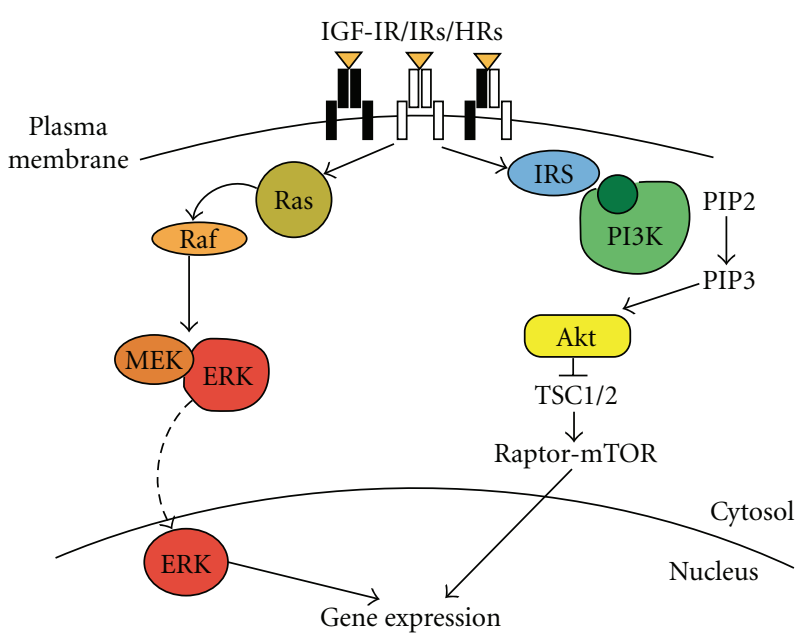

(b)

FIGURE 1: The IGF system: receptors, ligands, and signaling pathways. (a) Schematic representation of the major receptors and ligands involved in the IGF system. Insulin receptor isoforms (IR-A or IR-B) binds insulin with high affinity, while IGF-I receptor (IGF-IR) binds IGF-I and IGFII (left). In cells expressing both IR and IGF-IR, IR hemireceptors may heterodimerize with IGF-IR hemireceptors, leading to the formation of hybrid IR/IGF-IRs (HRs), which bind IGF-I and IGF-II with high affinity and insulin with a much lower affinity (right). (b) The IGF system signaling pathways. Schematic representation of the two major signaling pathways involved in IGF system. IGF-I, IGF-II, and insulin bind to their cognate receptors, leading to the activation of the PI3K/Akt/mTOR pathway and of the Ras/Raf-1/MEK/ERK pathway.

by the phosphoinositide-dependent kinase 1 (PDK1). Akt activation is crucial for the regulation of glucose metabolism but also for the regulation of cell size, proliferation and survival by regulating metabolic enzymes, such as glycogen synthase kinase 3 and 6-phosphofructo-2-kinase and apoptosis modulators, such as BAD. Akt also regulates mRNA translation through the raptor-mTOR pathway, which also has a central role in cell growth and metabolism [43, 44]. Activation of the raptor-mTOR complex requires the binding with Rheb (Ras homolog enriched in brain), a GTP-binding protein. Rheb binding to GTP is regulated by the TSC1/TSC2 heterodimeric complex that functions as a specific GTPaseactivating protein (GAP).

Akt phosphorylates and inactivates TSC2, thus increasing the amount of active GTP-Rheb that binds and activates the raptor-mTOR complex. Two main signaling pathways originate downstream the raptor-mTOR complex: the p70S6 kinase (p70S6K) and the eIF4E-binding protein 1 (4E-BP1) pathway. The p70S6K is a serine/threonine protein kinase, which regulates the synthesis of factors involved in the protein synthesis machinery, including the ribosomal 56 protein, and the translational regulators eukaryotic translation elongation factor 2 (eEF2) kinase and eukaryotic translation initiation factor $4 \mathrm{~B}$ (eIF-4B).

The $4 \mathrm{E}-\mathrm{BP} 1$ pathway regulates the activity of eukaryotic translation initiation factor $4 \mathrm{G}$ (eIF-4G) protein, which is involved in cap-dependent mRNA translation. After phosphorylation by raptor-mTOR, 4E-BP1 releases the eukaryotic translation initiation factor $4 \mathrm{E}$ (eIF-4E) allowing it to interact with eIF-4G, thus activating cap-dependent mRNA translation [45].

Akt also directly regulates gene transcription by promoting inactivation of transcription factors of the forkhead box "Other" (FoxO) family. In the basal state FoxO proteins are located in the nucleus where they activate the transcription of molecules relevant to metabolism, apoptosis promotion and cell cycle inhibition [46-49]. Following phosphorylation by Akt, FoxO factors are bound by 14-3-3 proteins and sequestered in the cytoplasm [50-52].

The PI3K/Akt pathway is negatively regulated by the lipid phosphatase PTEN, which dephosphorylates PIP3 [53]. PTEN activity is often reduced in cancer by mutations, underlying the key role of Akt pathway in cancer biology [54].

The second major signaling pathway downstream the IR and the IGF-IR involves Ras, a GTP-binding protein that cycles from the active (GTP-bound) to the inactive (GDP-bound) form [42]. Ras is activated by Ras guanine nucleotide exchange factor mSOS, which binds the SH3 domain of the adaptor Grb2. Grb2 couples the Ras/mSOS complex to the IR or IGF-IR by binding both to phosphorylated Shc and IRS proteins. Both IRS proteins and Shc compete for the same phosphosites on the receptor transmembrane domain [55]. After activation, Ras recruits to the membrane and activates the serine/threonine kinase Raf, which phosphorylates the dual specificity kinase MEK that in turn phosphorylates and activates ERK1/2 kinases. Inactive ERK1/2 is mainly located in the cytoplasm where it forms a MEK/ERK heterodimer [56]. After activation, ERK1/2 translocates to the nucleus where it phosphorylates a number of substrates involved in the transcription activation of several genes [42, 57, 58]. Moreover, activated ERK1/2 phosphorylates also numerous substrates in the cytoplasmic compartment implicated in cell growth and survival [58], such as p90 ribosomal S6 kinases (RSKs). RSKs inactivate proapoptotic proteins and contribute to positively regulate mRNA translation through p70S6K and 4EBP1. 
2.3. The IGF System in Cancer Development. Both epidemiological and experimental evidences have suggested a crucial role of the IGF system in cancer development and progression. Elevated plasma concentrations of IGF-I have been linked to an increased risk for several malignancies [59-62]. In particular, subjects with serum IGF-I levels in the upper quartile of the normal range have been shown to be at increased risk of premenopausal breast cancer and other cancers, such as prostate, lung, colorectal, endometrial and bladder as compared to subjects who have values in the lower quartile [34, 59, 60, 62, 63]. Evidences supporting a correlation between IGF-I levels and cancer risk arise also from acromegalic patients. Indeed, epidemiological studies suggest that high GH and IGF-I levels in acromegaly are associated with an increased incidence of various malignancies, including colon cancer [64].

More recently, it has also become evident that high circulating levels of insulin are an important factor of cancer promotion. Insulin resistance and associated compensatory hyperinsulinemia are common features of obesity and type 2 diabetes. In western countries obesity now occurs in approximately $30 \%$ of the general population and type 2 diabetes in $5-6 \%$. The prevalence of both these disorders increases with age. Both obesity and type 2 diabetes are associated with an increased risk for many forms of cancer, including cancer of the breast, colon, liver, pancreas, kidney and others $[7,8,65]$. Actually, hyperinsulinemia seems to be the major link between these disorders and cancer [4] and is also associated with a poor cancer prognosis [66].

Moreover, a variety of in vitro and in vivo studies have provided evidences of a complex dysregulation of the IGF system in cancer cells and have elucidated a few mechanisms by which this dysregulation may result in cancer promotion. The IR and the IGF-IR do not appear mutated in cancer but are often overexpressed [67-69]. With regard to IR, it is worth mentioning that only one of the two IR isoforms, the A isoform or IR-A, is overexpressed in cancer [70]. Interestingly, IR-A is a high affinity receptor not only for insulin but also for IGF-II [71]. As a further layer of complexity, cancer cells express high levels of IR/IGFIR hybrid receptors as a consequence of IGF-IR and IR overexpression [72].

Moreover, cancer cells often show abnormal autocrine/ paracrine production of both IGF-I and IGF-II, potent mitogens that bind both the IGF-IR and the IR-A [73, 74]. Several studies have demonstrated that forced expression of IGF-I and IGF-II in transgenic animal is associated with accelerated cancer development [75-78].

IGF system dysregulation/overactivation resulting from receptor and ligand abnormal expression may favor cancer progression by various mechanisms that depend on the constitutive activation of the two main branches of intracellular signaling, the PI3K/mTOR and the ERK1/2 signaling pathways. Interestingly, PTEN, a lipid phosphatase important for restraining the PI3K pathway, is often inhibited in human carcinomas and may contribute to the abnormal signaling of the IGF system [79]. This abnormal signaling leads to various effects, including upregulation of cyclin D1 and cyclin-dependent kinase 4 (CDK4), retinoblastoma (RB) phosphorylation and activation of cyclin $\mathrm{E}[80,81]$ and enhanced expression of matrix metalloproteases (MMPs) [82].

This eventually results in the promotion of cell proliferation and survival and enhanced cell migration [83]. Finally, the IGF-IR has also a crucial permissive role for anchorageindependent cell growth, which is strictly associated with the malignant phenotype $[84,85]$. In accordance with these findings, IGF-IR knocking-out prevents cell transformation by several oncogenes $[86,87]$. IR has similar although not identical effects as the IGF-IR. IR overexpression is also associated with a ligand-dependent transformed phenotype $[88,89]$ and is able to stimulate growth $[90,91]$ and chemotaxis [92, 93]. Finally, IGF system dysregulation in cancer induces resistance to radiation and various other targeted and nontargeted cancer therapies and has stimulated the development of therapeutical agents able to target IGF-IR signaling in cancer $[94,95]$.

\section{Anticancer Effects of PPAR- $\gamma$ Agonists}

3.1. PPARs Family, Expression and Ligands. PPARs (peroxisome proliferator activated receptors) belong to the nuclear receptor family, and recently have emerged as transcription factors that regulate diverse aspects of metabolism [96].

To day, three PPARs have been identified-PPAR- $\alpha$, PPAR- $\beta$ (known also as $\delta$ ) and PPAR- $\gamma$ (Figure 2(a)). PPAR$\alpha$ is expressed in liver, hearth, muscle and vascular wall whereas PPAR- $\beta / \delta$ is mainly expressed in skin, brain and adipose tissue $[9,97]$. PPARs regulate gene expression upon ligand binding that drives heterodimerization with the retinoid X receptor (RXR) and subsequent binding to specific response elements located in the promoter regions of target genes (Figure 2(a)).

Due to his abundance in adipose tissue, pancreatic $\beta$ cells, vascular endothelium and also in macrophages, PPAR- $\gamma$ is widely studied. Moreover, PPAR- $\gamma$ is the molecular target for the synthetic thiazolidinediones (TZDs), clinically used as insulin sensitizers in patients with type II diabetes. Seven PPAR- $\gamma$ mRNAs have been identified. PPAR- $\gamma-1$ and -2 are expressed mostly in adipose tissue and large intestine; lower levels are found in kidney, liver and small intestine. PPAR$\gamma-3$ is found in adipose tissue and large intestine, PPAR- $\gamma-4$ and -5 are expressed only in macrophages, whereas PPAR- $\gamma-6$ and -7 are found in adipose tissue [98].

The molecule of PPAR- $\gamma$ consists of an N-terminal domain (also called A/B domain), which is responsible for ligand-independent transcriptional regulation. The DNA-binding domain (or C) contains two zinc-finger-like and an $\alpha$-helical DNA binding motifs. Through the C domain, PPAR- $\gamma$ recognizes PPRE (Peroxisome Proliferators Response Element) sequences in the regulated promoter regions. In the $\mathrm{C}$-terminal is present the ligand-binding domain that potentiates the PPAR- $\gamma$ ability to dimerize with RXR and recruit coactivators, such as Steroid Receptor Coactivator 1 (SRC1), Peroxisome Proliferator Receptor- $\gamma$ Coactivator $1 \alpha$ (PGC-1 $\alpha$ ), TRAP220/PPAR $\gamma$ binding protein (PBP), and p300/CREB Binding Protein (CBP) (Figure 2(b)) [99-101]. The activation of PPAR- $\gamma$ by its ligands leads 
concomitantly to its ubiquitination and eventually to proteasome degradation.

The ligand-binding pocket of PPARs is larger than that of other nuclear receptors and allows the binding for a variety of ligands. In addition to TZDs (exogenous agonists), these ligands include peroxisome proliferators such as nanenopin, clofibric acid and warfarin $[102,103]$. Although endogenous ligands are yet not well defined, it has been shown that mono- and poly-unsaturated fatty acids and arachidonic acid metabolites may activate PPARs $[104,105]$.

3.2. PPAR- $\gamma$ and Cancer: Mechanisms Involving Differentiation, Proliferation and Apoptosis. TZDs have been used for the treatment of hyperglicaemia in type II diabetes since 1997. Troglitazone was the first of this class of drugs introduced into clinical practice, but it was withdrawn because of liver toxicity. Currently, pioglitazone and rosiglitazone are the only compounds licensed for the treatment of patients with type II diabetes.

Recently, the interest in TZDs as potential anticancer agents has been raised by observations that TZDs and other PPAR- $\gamma$ agonists possess PPAR- $\gamma$ dependent and independent antitumor effects [106]. Thus, TZDs in combination with chemotherapy drugs or other targeted therapies may represent a promising tool in the treatment of malignancies [106].

The molecular basis for the antitumor action of PPAR- $\gamma$ agonists remains incompletely elucidated. Numerous studies support the notion that PPAR- $\gamma$ activation induces apoptosis and thus exerts anticancer effects [107]. For instance, in lung cancer cells troglitazone triggered apoptotic response in PPAR- $\gamma$ and ERK1/2 dependent manner [108]. Troglitazone treatment reduced the antiapoptotic protein, Bcl2 , and caused nuclear accumulation and colocalization of PPAR- $\gamma$ and ERK1/2 [108]. Moreover, in anaplastic thyroid cancer, rosiglitazone-induced apoptosis was associated with a decrease of $\mathrm{Bcl}-\mathrm{X}_{\mathrm{L}}$ expression and caspase- 3 and -7 activation [109].

In addition to apoptosis, PPAR- $\gamma$ activation may reduce tumor development by halting cancer cell proliferation [110]. One well-know mechanism for suppressing proliferation involves cell cycle arrest. Cyclins are cell cycle regulators that specifically activate cyclin-dependent kinases (CDKs). Due to their role in cell cycle control, cyclins are potential oncogenes: in fact, cyclin D1 is overexpressed or amplified in several human cancers $[111,112]$.

Exposure to TZDs for 24 hours may cause $G_{0} / G_{1}$ cell cycle arrest $[113,114]$. TZD treatment not only decreased protein levels of cyclin D1, but also reduced proliferating cell nuclear factors such as $\mathrm{pRb}$ and Cdk4, and increased the cyclin-dependent kinase inhibitors p21 and p27, in a time dependent manner [114]. Again, in thyroid anaplastic cancer rosiglitazone induced growth arrest increasing cyclin-dependent kinase inhibitors p21 and p27, reducing cyclin $\mathrm{D} 1$ expression as well as activating $\mathrm{Rb}$ protein [109].

Another mechanism by which PPAR- $\gamma$ activation may act as tumor suppressor is through the promotion of cellular differentiation. In cultured breast cancer, PPAR- $\gamma$ ligands caused extensive lipid accumulation and changes in epithelial gene expression associated with a more differentiated, less malignant state [115]. In lung cancer cells, ciglitazone induced differentiation [116] and in thyroid cancer cells, rosiglitazione induced the expression of thyroid-specific differentiation markers suggesting a partial reversion of the epithelial mesenchymal transition [109].

The mechanism of TZD-induced differentiation has also been well studied in adipocytes and involves the interaction with the Wnt pathway. It has been shown that PPAR- $\gamma$ and GSK3 $\beta$ interact through CAAT/enhancer binding proteins (C/EBP). GSK $3 \beta$-induced C/EBP $\beta$ activates PPAR- $\gamma$, that in turn activates the differentiating factor $\mathrm{C} / \mathrm{EBP} \alpha$ leading to the production of adiponectin and completion of adipocyte differentiation $[117,118]$.

Moreover, PPAR- $\gamma$ and $\beta$-catenin expression seems to be correlated [119]. Direct interactions among PPAR- $\gamma$, RXR and $\beta$-catenin have been found recently in human kidney embryonic HEK293 cells and in human metastatic prostate cancer LNCaP cells $[120,121]$. PPAR- $\gamma$ can function to suppress Wnt signaling by targeting phosphorylated $\beta$ catenin to proteasome. In agreement with these findings, in 3T3-L1 adipocytes, $\beta$-catenin mRNA and protein levels were decreased by PPAR- $\gamma$ activation [122]. The above data imply a positive feedback mechanism involving GSK3 $\beta$, PPAR$\gamma$ and $\beta$-catenin that amplifies signals for differentiation and inhibits signals for proliferation in both adipocytes and cancer cells.

Another mechanism by which PPAR- $\gamma$ agonists may mediate suppression of tumor initiation and progression is the inhibition of angiogenesis and the downregulation of tumor microenvironment inflammation $[123,124]$. The PPAR- $y$ antiinflammatory actions are of relevance to the treatment of atherosclerosis as well as cardiovascular disease [125]. However, given the association of chronic inflammation with cancer risk, they may also prove important for the treatment and prevention of cancer.

In summary, PPAR- $\gamma$ agonists may act as negative regulators of cancer growth and progression, by multiple mechanisms. Some of these effects may be related to the direct and/or indirect interaction of PPAR- $\gamma$ agonists with the IGF system. We will herein review the molecular mechanisms by which PPAR- $\gamma$ agonists cross-talk with the IGF-system signaling and may affect cancer biology.

\section{Cross-Talk between PPAR- $\gamma$ Agonists and IGF System Signaling}

Conflicting evidence has led to confusion about whether PPAR- $\gamma$ exerts an inhibitory or stimulatory effect on tumorigenesis (Table 1). It is generally considered as a tumorsuppressor, yet has been suggested to exacerbate the growth of certain tumors. The janus-face (anti- versus protumor function) of PPAR- $\gamma$ and its ligands, can be explained by considering the interaction with IGF system and its downstream signaling pathways as MAPK, PI3K and mTOR (Figure 3). 


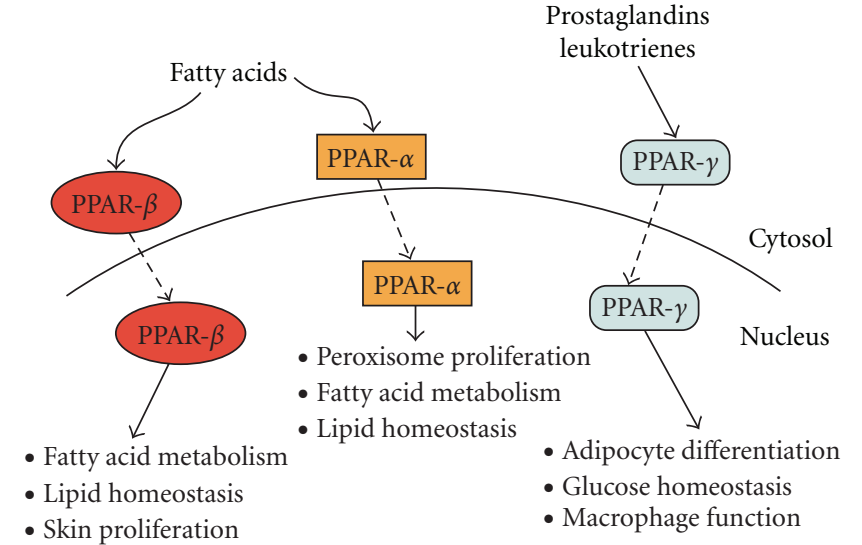

(a)

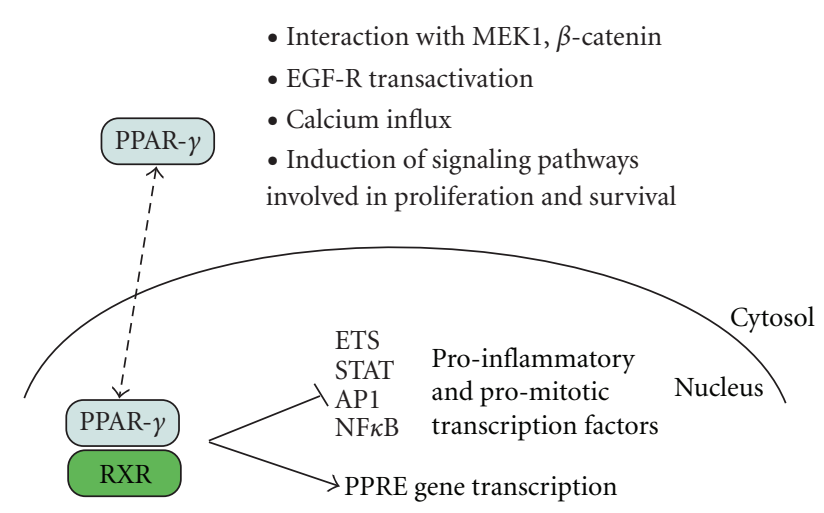

(b)

FIGURE 2: Components and signaling pathways of the PPAR system. (a) Schematic representation of components of the PPAR system. PPARs act as ligand-activated transcription factors that are responsive to the lipid status of the cell. The physiological ligands for these nuclear receptors are typically unsaturated fatty acids (FFAs) and their eicosanoid products. PPARs regulate the expression of genes that encode proteins involved with lipid metabolism (oxidation), leukotriene degradation, energy balance, eicosanoid signaling, cell differentiation and tumorigenesis. PPARs are differentially expressed in the various tissues. PPAR- $\alpha$ is highly expressed in liver, kidney, heart, brown adipose tissue, and the intestine, whereas PPAR- $\gamma$ is found in adipose tissue, small intestine, and lymphatic tissues. PPAR- $\beta$ is ubiquitous. (b) PPAR$\gamma$ genomic versus nongenomic actions. PPAR- $\gamma$ belongs to the class of nuclear receptors, with a typical modular structure composed by at least an $\mathrm{N}$-terminal transactivation domain and a DNA binding domain (DBD). Upon ligand binding, a conformational change leads to the release of corepressors (NCoRs), recruitment of coactivators (NCoAs), heterodimerization and transactivation of PPRE-related promoters. This genomic function of PPAR- $\gamma$ controls immune response, as well as lipid and glucose metabolism. Nuclear PPAR- $\gamma$ exerts also a negative cross-talk towards major proinflammatory and promitotic transcription factors. Cytoplasmic PPAR- $\gamma$, by interacting with proteins (MEK1, $\beta$-catenin) and activating transmembrane proteinases, elicits rapid and transient nongenomic effects that modulate EGF-R transactivation, calcium influx, and PI3K/Akt, IKK/NF $\kappa \mathrm{B}$ and MAPKs signaling pathways.

TABLE 1: Mechanisms underlying PPAR- $\gamma$ pro- and antitumorigenic effects.

\begin{tabular}{lc}
\hline Protumorigenic effects & References \\
\hline $\begin{array}{l}\text { (1) Inhibition of PPAR- } \gamma \text { genomic } \\
\text { functions by MAPK }\end{array}$ & {$[108,126-143]$} \\
$\begin{array}{l}\text { (2) PPAR- } \gamma \text { nongenomic functions } \\
\text { (MAPK activation, MMP2, and VEGF }\end{array}$ \\
production) & \\
\hline Antitumorigenic effects & References \\
\hline $\begin{array}{l}\text { (1) PPAR- } \gamma \text { genomic effects } \\
\text { (2) Induction of PTEN expression }\end{array}$ & {$[109,144-151]$} \\
(3) Inhibition of p70S6K & \\
\hline
\end{tabular}

\subsection{PPAR- $\gamma$ and MAPK Cross-Talk: A Complex Issue Affecting} IGF Signaling. As we have already mentioned in the previous section (the IGF system signaling pathways) the MAPK cascade transmits proliferative signals generated by cell surface receptors and cytoplasmic elements to the nucleus $[152,153]$.

The RTK-Ras/Raf/Mek/Erk pathway is overactivated in $\sim 30 \%$ of human cancers [154] where it provides growth and survival signals. Growth factors can be overexpressed and receptor tyrosine kinases mutated or amplified, thereby stimulating constitutive receptor tyrosine kinases signaling [155]. One of the upstream regulators of MAPK pathway is the IGF signaling axis. The binding of IGF-I or IGF-II to the IGF-IR initiates conformational changes that triggers autophosphorylation and subsequent activation of Ras/Raf/Mek/Erk cascade. Thus, the IGF system deregulation through either (i) IGF-IR overexpression or (ii) autocrine/paracrine production of IGF-I and IGF-II or (iii) autocrine IGF-II/IR-A loop activation, can induce constitutive stimulation of the MAPK cascade.

The IGF mediated MAPK activation, in turn, may modulate the genomic activity of PPAR- $\gamma$ by the inhibition of its antiproliferative and prodifferentiating functions, thereby contributing to the tumor promoting role of IGF pathway.

The points of interactions between MAPK pathway and PPAR $\gamma$ are various $[156,157]$ and include the following.

(1) Phosphorylation of a serine residue of PPAR- $\gamma$ (and its cofactors) by ERK1/2, JNK and p38 MAPKs (Figure 3(D)) [158]. Phosphorylation of PPAR- $\gamma$ by MAPKs is directed against Ser82/112 (mouse) or Ser84/114 (human) within a consensus MAPK-motif (PxSPP) [159, 160]. This MAPKdependent mechanism, modulates the ability of PPAR- $\gamma$ to form a heterodimer with $\mathrm{RxR}$ and bind PPRE, thus inducing gene transcription (genomic activity of PPAR$\gamma)$ [161]. The PPAR- $\gamma$ conformational change, induced by phosphorylation, inhibits its ligand-binding affinity [162], decreases its binding to PRRE [163] and the recruitment of coactivator/corepressor complexes [164]. Moreover, PPAR- $\gamma$ phosphorylation promotes its inactivation by polyubiquination, proteasomal degradation and sumoylation [165]. The suppression of PPAR- $\gamma$ genomic activity, by MAPK-mediated phosphorylation, is in concordance with 


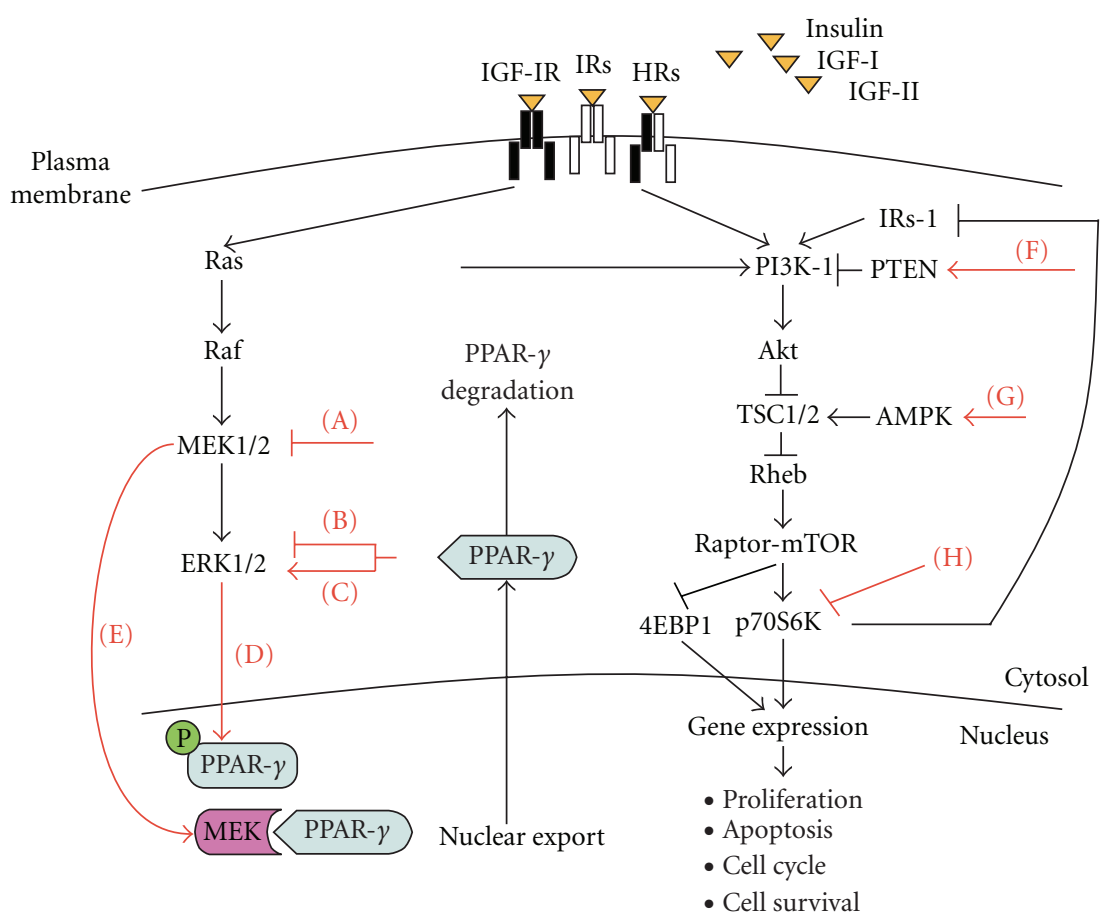

FIGURE 3: Cross-talk between PPAR- $\gamma$ and IGF system downstream signaling pathways. The points of interaction between PPAR- $\gamma$ and MAPK/PI3K pathways occur at different levels and are indicated as arrows (activation) or bars (inhibition). In some cell contexts PPAR$\gamma$ ligands reduce MEK1/2 protein expression (A) and inhibit ERK1/2 phosphorylation (B). However, in other cell systems, PPAR- $\gamma$ agonists may activate ERK1/2 (C). Alternative mechanisms of interaction between PPAR- $\gamma$ and MAPK/PI3K pathways include (D) ERKmediated PPAR- $\gamma$ phosphorylation at Ser84/114; (E) MEK1/2-dependent PPAR- $\gamma$ nuclear export followed by PPAR- $\gamma$ degradation; (F) PTEN upregulation; $(\mathrm{G})$ mTOR downregulation via activation of AMPK; $(\mathrm{H})$ inhibition of p70S6K phosphorylation.

the antiproliferative, antiinflammatory and prodifferentiating role of PPAR- $\gamma$ and is supported by several in vitro studies, conducted in normal as well as in cancer cells. For example, it has been shown that TFN $\alpha$ suppresses PPAR- $\gamma$ function in hepatic stellate cells [126] as do the PGF2 $\alpha$ in adipocytes [127], proinflammation lipid mediators HODEs in colon and prostate cancer cells [128], EGF and PDGF in preadipocytes (3T3-L1) and in murine fibroblasts (NIH3T3) $[129,130]$. In addition, other studies have revealed the poly-ubiquination and proteasomal degradation upon S82/112 phopshorylation of PPAR- $\gamma$ as a mechanism of PPAR- $\gamma$ inactivation in adipocytes [131, 132], breast [133] and colon cancer cells [134], after IFN $\gamma$, Her-2 and gastrin stimulation, respectively.

In summary, altogether, these in vitro evidences indicate that MAPK stimuli, through phosphorylation, inactivate PPAR- $\gamma$-dependent gene transcription in cancer cells and are in line with the antitumor promoting role of PPAR- $\gamma$ $[135,136]$.

(2) Modulation of PPAR- $\gamma$ 's nucleo-cytoplasmic compartmentalization induced by MEK1, upon cell stimulation with mitogens and PPAR- $\gamma$-ligands (Figure 3(E)).

Burgermeister et al. [131] have demonstrated that MEK1 and PPAR- $\gamma$ directly interact in resting cells and this association induces a nuclear export of PPAR- $\gamma$, leading to reduction in its genomic functions. Cytosolic PPAR$\gamma$, then, is either subjected to proteosomal degradation or shunted to other cell compartments (ER/Golgi, cytoskeleton, lipid droplets, caveolae) to trigger extranuclear/nongenomic actions. Although the functions of exported PPAR- $\gamma$ remain to be completely elucidated, it seems that this dynamic change in subcellular localization of PPAR- $\gamma$ may influence the balance between its tumor suppressive and tumor promoting activities. Several studies have reported that PPAR- $\gamma$ is mainly present in the nucleus of non neoplastic tissues, where it exerts classical genomic functions (antiinflammatory, antiproliferative, prodifferentiating). In contrast, it is expressed predominantly in the cytoplasm of tumor tissues of infiltrating breast carcinoma and salivary duct carcinoma, where it is associated with increased tumor aggressiveness and poor clinical prognosis of patients [137, 138]. A differential subcellular distribution of PPAR- $\gamma$ has also been shown in human stomach cancer tissues, where the nucleo : cytoplasm ratio of PPAR- $\gamma$ increased along with the progression of intestinal metaplasia to undifferentiated cancer [166]. Notably, in lung tumor samples, PPAR$\gamma$ expression was present in both the nucleus and the cytoplasm [167]. These results are indicative of a correlation between cell malignancy and PPAR- $\gamma$ subcellular distribution.

In summary, both mechanisms of MAPK/PPAR- $\gamma$ interaction described above (i.e., the MAPK-mediated PPAR$\gamma$ phosphorylation as well as the MEK-1 driven nucleocytoplasmic shuttle of PPAR- $\gamma$ ), may represent a way for enabling PPAR- $\gamma$ nuclear genomic activity and support the protumor and antiapoptotic role of IGFI system and 
its downstream signal-transduction components Ras/Raf/ MEK/ERK.

(3) Inhibition of MAPK pathway mediated by PPAR- $\gamma$ ligands.

In some cell contexts and tissue-specific systems, it has been shown that PPAR- $\gamma$ agonists specifically abolished the phosphorylation of ERK1/2 in a dose and time dependent manner (Figure 3(B)) and also downregulated the protein expression of MEK1/2 (Figure 3(A)), inducing cell growth arrest and apoptosis [137, 168]. The inhibition of MAPK signals mediated by PPAR- $\gamma$ ligands, is in line with their antiproliferating and proapoptotic functions and is in concordance with data from literature showing that PPAR- $\gamma$ agonists block the biological actions of IGF-I.

The implication of these findings is that PPAR- $\gamma$ agonists may represent a reasonable therapeutic approach in tumors where MAPK and/o IGF-I pathways are overactivated. However, several in vitro and in vivo studies have provided evidences indicating that PPAR- $\gamma$ ligands may also trigger promitotic and prosurvival signals in certain cell contexts. It is well known that PPAR- $\gamma$ agonists exhibit rapid (within 15 minutes) non genomic effects, including activation of signaling pathways as MAPK and PI3K/mTOR [139], upregulation of p21 and p27 [140, 169], induction of p53 [170], transient alterations in mitochondrial functions [171]. An early response of ERK1/2 in presence of PPAR$\gamma$ ligands has been reported in many studies and occurs under largely unknown mechanisms, which may or may not involve PPAR- $\gamma$. Takeda et al. [172] demonstrated that 15d-PGJ2 and thiazolidinediones activate the MEK/ERK pathway through PI3K pathway, leading to c-Fos mRNA expression and DNA synthesis [108, 141]. Ciglitazone and 15d-PGJ2 induce activation of MAPKs in primary astrocytes, preadipocytes, chondrocytes and liver epithelial cells through a PPAR- $\gamma$ independent mechanism $[142,168]$. Patel et al. [140] have reported that troglitazone activates both PI3K and MAPK signaling networks. Furthermore, in colon carcinoma cells, it has been found that tiazolidinediones, through ROS production and ERK activation, induce matrix metalloproteinase 2 (MMP2) and subsequently increase tumor cell invasion [142]. Yet, in human breast cancer cells MCF7, 15d-PGJ2 upregulates VEGF and induces PPAR$\gamma$-independent ERK activation, thereby stimulating angiogenesis and proliferation [143]. This positive cooperation between PPAR- $\gamma$ and components of MAPK cascade in promoting tumor initiation and progression may explain the absence of therapeutic benefits of TZDs in some cancer patients and adds significant complexity to the PPAR- $\gamma$ functions in cancer biology. Furthermore, the nongenomic rapid activation of ERK signaling cascade, in presence of PPAR- $\gamma$ ligands, can affect the PPAR- $\gamma$ genomic action, via ERK1/2 - mediated PPAR- $\gamma$ phosphorylation or via MEKdependent PPAR- $\gamma$ nuclear export. This overlap between genomic and nongenomic effects of PPAR- $\gamma$ ligands, may explain both pro- and antitumor actions of PPAR- $\gamma$ agonists. However, nowadays, the mechanisms underlying cell decision for pro- versus antiproliferative responses upon PPAR- $\gamma$ ligands stimulation, are unknown.
So far, PPAR- $\gamma$ emerges as a context-specific tumor modulator, whose functions are modulated by PPAR- $\gamma$ independent effects of its ligands and by a synergic or antagonistic cooperation with IGF-I/MAPK cascades. It is possible to speculate that in tumors where PPAR- $\gamma$ expression/activity is low and the MAPK signaling network is constitutively activated by various stimuli, including IGF dependent signals, PPAR- $\gamma$ ligands exert antitumor and antiproliferating effects. In this condition, the combined use of kinase inhibitors and PPAR- $\gamma$ agonists may be beneficial as anticancer therapeutic strategy. Alternatively, the interactions between PPAR- $\gamma$ and other important survival pathways, such as PI3K/mTOR, may influence cell fate and determine whether pro- or antitumorigenic responses are induced. In light of these considerations, elucidating the non genomic pathways of PPAR- $\gamma$ ligands and delineating the transduction signals underlying the cross-talk between PPAR- $\gamma$ and other key survival signals is likely to yield new therapeutic targets for development of anticancer therapies.

4.2. Cross-Talk between PPAR- $\gamma$ and PI3K. Besides the MAPK cascade, alternative antiapoptotic and prosurvival signal transduction pathways, such as PI3K and mTOR, have been identified for the IGF-IR signaling axis (for a detailed description see Section 2.2).

The points of interaction between PPARs family and PI3K pathway involve different components of IGF-I/PI3K signaling cascade.

For example, as shown in adrenocortical cancer cells (SW13 and H295R), PPAR- $\gamma$ ligands can rapidly interfere with the Akt phosphorylation/activation, which mediates IGF-I stimulated proliferation [173]. These evidences support the antiIGF-I role of PPAR- $\gamma$ agonists observed in a wide variety of tumor cancer cell lines and tissues. A possible mechanism for this antagonistic effect is the increase in PTEN expression (Figure $3(F)$ ). In line with this hypothesis, we have found that in human anaplastic cancer cell lines, rosiglitazone, via PTEN upregulation, inhibited IGF-I mediated biological effects such as cell migration, survival and anchorage-independent growth [109]. Similar results have been reported in human hepatocarcinoma cell lines (BEL-7404 and Hep3B) [144, 145] as well as in colon cancer cells (Caco2) [146], in breast cancer cells (MCF-7) [146], in nonsmall cell lung carcinoma cells (H1792, H1838 and A549) [147, 148], and in pancreatic cancer cells (AsPC1) [149]. However, the exact molecular mechanism behind PTEN induction, due to PPAR- $\gamma$ agonists, has yet to be fully understood. Two hypotheses have been proposed to explain the interaction between PTEN and PPAR- $\gamma$ : PPAR$\gamma$ directly regulates PTEN transcription and/or PPAR- $\gamma$ regulates secondary unknown factors that, in turn, regulate PTEN [146, 174]. Furthermore, because PTEN expression can be regulated by interfering with its transcription activity or by inducing posttranscriptional modifications, it is also possible that PPAR- $\gamma$ agonists induce PTEN overexpression by decreasing its degradation $[175,176]$. Aside from the specific mechanisms involved, the regulation of PTEN levels by PPAR $\gamma$ agonists, provides a powerful mechanism to shut down the basal or stimulated signals of PI3K cascade and 
could be exploited for future treatment of cancers in which PTEN is downregulated/lost and IGF-I-mediated signals are amplified.

The link between PPAR- $\gamma$ and PI3K pathway involves also another component of $\mathrm{PI} 3 \mathrm{~K}$ signaling axis: the mTOR/p70S6K cascade. As we have previously discussed, mTOR pathway is coregulated by IGF-I-Akt signaling to ensure both a reasonable level of nutrients and a positive mitogen signal for cell growth and division. The IGF-I system regulates the mTOR axis through the phosphorylation and inhibition of the TSC1/2 complex by Akt, which in turn activates Rheb and mTOR. Stimulation of the IGFIR activates the PI3K/Akt/mTOR cascade and triggers an mTOR-dependent decrease in IRS-1 expression and phosphorylation, leading to PI3K/Akt/mTOR inactivation [177, 178]. This feedback inhibition could paradoxically reduce the antitumor effect of mTOR inhibition by enhancing IGF-I signaling.

Thiazolidinediones have been recently shown to modulate and regulate the IGF-I/Akt/mTOR/p70S6K pathway. In endothelial cells, troglitazone has been found to decrease p70S6K phosphorylation (Figure $3(\mathrm{H})$ ) and to inhibit protein biosynthesis via a protein phosphatase 2A (PP2A)dependent mechanism, which do not involve neither mTOR nor PPAR $\gamma$ [150]. An alternative mechanism through which PPAR $y$ agonists inhibits phosphorylation of p70S6K is the activation of AMPK (Figure $3(\mathrm{G})$ ) [151]. AMPK is a multisubstrate enzyme induced by increase in AMP level during metabolic stress in response to exercise, hypoxia and fasting condition and it plays a major role in the regulation of energy control [179]. The phosphorylation of this fuelsensing enzyme, negatively regulates mTOR by directly phosphorylating the TSC1/2 complex [180]. The mTOR inhibition induced by AMPK is in line with the existence of a link between AMPK and the growth inhibition of some cancer cells $[179,181,182]$. The activation of this enzyme induced by thiazolidinediones has been supported by several in vitro studies. As $\mathrm{He}$ et al. [151] have reported, PPAR $\gamma$ agonists induced phosphorylation of AMPK in mouse skin keratinocytes most likely via a PPAR $\gamma$-indipendent mechanism, which subsequently suppresses IGF-I-induced cell proliferation by inhibiting mTOR activity and phosphorylation of p70S6K. Yet, Han and Roman [147] have found that rosiglitazone inhibits growth of nonsmall cell lung carcinoma cells via upregulation of AMPK, thereby downregulating the mTOR/p70S6K pathway through PPAR $\gamma$-dependent and/or PPAR $\gamma$-independent mechanisms. Although it is not well known how thiazolidinediones rapidly activate AMPK, the subsequent inhibition of mTOR signaling pathway can be considered a mechanism by which thiazolidinediones exert an antiIGF-I function as well as an insulin-sensitizing action.

As thiazolidinediones target both the IGF system and other crucial protumor signals downstream of IGF-IR, their use in monotherapy or in combination with the small-molecule TK inhibitors or with antibodies directed against the IGF-IR, may be effective to achieve the maximal therapeutic benefit and may even be useful to reduce the side effects associated with IGF-IR targeted therapy (insulin resistance, hyperglycaemia, hyperinsulinaemia, effect on growth and development of normal cells and tissues with high level of cellular turnover, neurotoxicity), thereby improving tolerability and/or efficacy. Furthermore, the use of PPAR $y$ agonists may represent a valid therapeutic tool to circumvent the resistance that some tumors develop to therapies targeting $\mathrm{PI} 3 \mathrm{~K} / \mathrm{mTOR}$ signaling pathways.

4.3. PPAR- $\gamma$ Agonists May Regulate IGFs Bioavailability. Hyperinsulinemia and insulin resistance, commonly observed in type 2 diabetes and others metabolic disorders, are associated with an increased risk of tumor development in several tissues. Compensatory activation of IGF-I signaling in insulin resistance states is believed to be responsible for this association [37, 183]. Thiazolidinediones are currently used to treat type 2 diabetes mellitus and, by ameliorating insulin resistance, have the potential to reduce IGF-I bioavailability in these patients. Furthermore, inhibiting the tumor promoting activity of IGF-I they may provide additional tumor preventive benefit to type 2 diabetes patients. The local availability of IGFs ligands is abnormally high in many cancers where they serve as endocrine, autocrine and paracrine regulators of survival and proliferating signals mediated by IGF-IR. The IGFs bioavailability, as well as the IGFs bioactivity, is modulated by IGF-I binding proteins (IGFBPs) and IGFP proteases. In general, IGFBPs limit IGFs access to IGF-IR, reducing the bioactivity of these growth factors. However, in some cell contexts, IGFBPs can increase rather than decrease IGF-mediated effects, by presenting and slowly releasing IGF-I for receptor interactions, while protecting the receptor from IGF-I induced downregulation [35]. This phenomenon has been shown for IGFBP1, IGFBP3 and IGFBP5 [37, 184]. Furthermore, IGFBPs (especially IGFBP3) may also regulate cell growth and apoptosis in IGF-I independent manner [185]. Alterations of individual components of IGF cascade (IGFs/IGF-IR/IGFBPs) may potentially contribute to cancer initiation and progression [186]. Several evidences have suggested that the effects of TZDs on cell proliferation and differentiation can be due to a modulation in IGFs/IGFBPs levels. Lecka-Czernik et al. [187] reported, that, in primary and transformed marrow stromal cells and in mouse liver cells, rosiglitazone, suppresses IGFI, IGFII and IGFBP-4 levels and reduces the expression of IGFI$\mathrm{R}$ and IGFII-R, whereas no effect was observed in IGFBP3 expression. These changes in IGF signaling effectors were evident within 72 hours and occurred at transcriptional as well as posttranscriptional levels. In addition, the modulation of the IGF system mediated by PPAR $y$ ligands, was associated with suppression in several cell cycle genes. These findings are in line with other reports demonstrating the antiproliferative effect and the antiIGF-I role of PPAR $y$ agonists $[96,188]$. Although the PPAR $\gamma$ mediated suppression of IGF-I levels could limit cell proliferation and induce apoptosis in specific cell context, the authors pointed out that the drop in circulating IGF-I may negatively impact the skeleton, by impairing osteoblastic differentiation and action [187]. These observations may have clinical significance and should be taken into account when TZDs are used in young patients that are still acquiring peak bone mineral 
density. However, further studies are needed to better understand the role of IGF-I in bone cell turnover. Interactions between PPAR $y$ and IGF-I signaling mediators have also been seen in human ovarian cells. In experiments carried out in vitro, TZDsincrease IGFBP-1 production by ovarian cells in the absence of insulin but enhanced insulin-mediated inhibition of IGFBP-1 production. The latter insulin sensitizing effect, could increase the bioavailability of IGFs, thereby enhancing the IGF-I mediated ovarian follicle proliferation and steroidogenesis [189]. These opposite effects on IGFBP-1 production (insulin-independent stimulation versus insulindependent inhibition) observed in vitro, contrast with in vivo data showing that TZDs increase of IGFBP-1 synthesis, presumably because they reduce hyperinsulinemia [190]. Stimulation of insulin receptor or IGF-IR as well as the modulation of circulating IGFBP-1 levels by TZDs may increase ovarian sensitivity to insulin and/or IGFs. The subsequent effect is the reduction of ovarian androgen production and the improvement of ovulatory function [191]. Although the role of TZDs in mediating ovarian function through IGFBP-1 synthesis modulation needs to be clarified, the interactions between PPAR $\gamma$ agonists and IGF system may be important under both physiological (ovulation and steroidogenesis) and pathological conditions (polycystic ovary syndrome and syndromes of extreme insulin resistance). The effect of PPAR $\gamma$ agonists on IGFBP1 production has also been studied in HepG2 hepatoma cells. In these cells, troglitazone is able to increase IGFBP1 mRNA expression and secretion in a PPAR $\gamma$ independent manner [192]. IGFBP-1 mediates critical prosurvival signals in liver, although it has also been shown to inhibit the antiapoptotic IGFs functions. Nowadays, the exact role of IGFBP-1 production in liver cells upon PPAR $\gamma$ agonists treatment, is yet not understood. The variety of the effects induced by TZDs on components of IGF-I system is still under investigation and may be due to the multiple and alternative signaling pathways they stimulate or inhibit. This adds significant complexity in the understanding of PPAR $\gamma$ agonists functions in both physiological and pathological conditions.

4.4. PPAR- $\gamma$ Agonists: In Vivo Studies. The role of PPAR- $\gamma$ as a key regulator of metabolism is mainly mediated through its transcription factor activity in adipose tissue, muscle and liver. Studies in knock-out mice have elucidated this role and have demonstrated that insulin sensitization, through PPAR$\gamma$ action, involves adipose tissue maintenance [193-195].

The activated receptor works in a number of ways to achieve these effects, including alteration of the expression of genes involved in lipid metabolism, free fatty acid (FFA) uptake and storage in adipose tissue [196, 197]. Moreover, PPAR- $\gamma$ activation by TZDs has been shown to reduce the amount of circulating FFA via adipocyte differentiation and apoptosis [198]: the number of small adipocytes, able to accumulate FFA, increases at the expense of hypertrophied ones that release FFA. As consequence, adipose tissue mass is increased, so other insulin-sensitive tissues are in an advantaged position. Glucose metabolism by liver and muscle is improved and $\beta$-cell apoptosis decreased, thereby increasing insulin secretion in type II diabetic patients. Another important effect of PPAR- $\gamma$ activation is connected with increased adiponectin production from adipose tissue [196, 199]. Adiponectin significantly increases fatty acid oxidation in human skeletal muscle via activation of AMPactivated protein kinase, again with increased glucose uptake [199].

4.5. Effects on Insulin Serum Level and Circulating IGF-I. TZDs are useful agents in the treatment of hyperglycaemia, acting as insulin sensitizers and enhancing glucose uptake via their interactions with PPAR- $\gamma$ receptors. As already mentioned, in vivo experiments in diabetic mice confirm that treatment with PPAR- $\gamma$ agonists resulted in significantly improved glycaemia and increase in circulating adiponectin levels [200, 201].

Clinical trials have shown that TZDs lower fasting and postprandial glucose and it has been demonstrated that pioglitazone and rosiglitazone at maximal doses can lower glycosilated haemoglobin by $1-1.5 \%$, on average [9]. Moreover, it has been shown that treatment with rosiglitazone slowed progression to monotherapy failure more effectively than metformin or glyburide. Rosiglitazone was also shown to slow the rate of loss of $\beta$-cell function and improve insulin sensitivity to a greater extent than the other two drugs [202].

Despite the growing amount of clinical data supporting the role of PPAR- $\gamma$ agonists as insulin-sensitizers, only a small number of in vivo studies is available regarding the effect of PPAR- $\gamma$ ligands on IGF-I serum level.

Nonetheless, current studies provide some essential and encouraging information. Lecka-Czernik et al. [187] have recently focused their attention on $\operatorname{PPAR}-\gamma$ role in the acquisition and maintenance of bone mass. In yellow obese agouti mice, rosiglitazone treatment for 8 week lowered serum IGF-I and reduced IGF-I transcript in liver and peripheral fat. Similarly, Ackert-Bicknell et al. [203] have recently analyzed strain specific effects of rosiglitazone on bone mass, body composition and serum IGF-I levels. They found that in the $\mathrm{C} 3 \mathrm{H}$ strain, rosiglitazone affects adiposity and decreased circulating IGF-I levels.

\section{Concluding Remarks}

It is now widely accepted that IGF system dysregulation plays an important role in the development of common human malignancies. Cancer cells often overexpress IGF-IR and IR-A. Moreover, signaling downstream of these receptors is frequently constitutively activated by autocrine/paracrine production of IGF-I and/or IGF-II.

In addition, hyperinsulinemia, an important feature associated with the insulin resistance of obesity and type 2 diabetes may stimulate IGF-IR and IR-A in cancer cells and play a key role in cancer promotion [204-207]. Circulating levels of IGF-I in the upper quartile of the normal range may also promote cancer, especially at critical ages such as childhood and adolescence [36].

The pleiotropic effects of PPAR- $\gamma$ agonists have several potential beneficial effects in cancer therapy. Not only PPAR$\gamma$ agonists downregulate both the PI3K and the Ras pathway, 
which are the two main signaling pathways downstream receptors of the IGF system, but also they ameliorate insulin resistance and lower circulating levels of insulin and free IGFI. One may hypothesize that the janus-face (anti- versus protumor function) of PPAR- $\gamma$ and its ligands can be explained by the interaction with IGF system and that anticancer effects are mainly to be expected in those tumors "addicted" to the enhanced IGFs signaling. Only scanty data are currently available regarding the antitumor effect of PPAR- $\gamma$ agonists in the clinical setting $[17,106,108,208]$ and more work is needed in this field. Some disappointing results in clinical studies may be explained by the inclusion of cancers in far advanced stages. Moreover, in future trials we probably need to include tumors characterized by IGF system overactivation and/or tumors occurring in hyperinsulinemic patients. Finally, in vitro and in vivo studies have demonstrated that combination therapies, with PPAR- $\gamma$ agonists together with other anticancer drugs, including drugs targeting the IGF system, may provide benefit for the treatment of certain human cancers. The most promising drugs able to potentiate the antiproliferative effect of PPAR- $\gamma$ agonists are platinumbased chemotherapics, COX-2 inhibitors, paclitaxel, EGFR tyrosine kinase inhibitors, mTOR antagonists and IGF-IR inhibitors $[148,209-212]$. Although combination therapies using these agents have been suggested to be effective in terms of antitumor activity and prevention of drug resistance, large randomized clinical trials are required for further evaluation and optimization.

\section{Acknowledgment}

Grants from the Associazione Italiana per la Ricerca sul Cancro (AIRC), PRIN-MIUR 2005, e Ministero della Salute (Ricerca Finalizzata) to AB.

\section{References}

[1] E. K. Maloney, J. L. McLaughlin, N. E. Dagdigian, et al., "An anti-insulin-like growth factor I receptor antibody that is a potent inhibitor of cancer cell proliferation," Cancer Research, vol. 63, no. 16, pp. 5073-5083, 2003.

[2] K. Garber, "IGF-1: old growth factor shines as new drug target," Journal of the National Cancer Institute, vol. 97, no. 11, pp. 790-792, 2005.

[3] M. A. Soos, B. T. Nave, and K. Siddle, "Immunological studies of type I IGF receptors and insulin receptors: characterisation of hybrid and atypical receptor subtypes," Advances in Experimental Medicine and Biology, vol. 343, pp. 145-157, 1993.

[4] P. Pisani, "Hyper-insulinaemia and cancer, meta-analyses of epidemiological studies," Archives of Physiology and Biochemistry, vol. 114, no. 1, pp. 63-70, 2008.

[5] Z. Huang, N. L. Bodkin, H. K. Ortmeyer, B. C. Hansen, and A. R. Shuldiner, "Hyperinsulinemia is associated with altered insulin receptor mRNA splicing in muscle of the spontaneously obese diabetic rhesus monkey," The Journal of Biological Chemistry, vol. 94, no. 3, pp. 1289-1296, 1994.

[6] A. M. Fair, Q. Dai, X.-O. Shu, et al., "Energy balance, insulin resistance biomarkers, and breast cancer risk," Cancer Detection and Prevention, vol. 31, no. 3, pp. 214-219, 2007.
[7] P. Vigneri, F. Frasca, L. Sciacca, L. Frittitta, and R. Vigneri, "Obesity and cancer," Nutrition, Metabolism and Cardiovascular Diseases, vol. 16, no. 1, pp. 1-7, 2006.

[8] H. D. Strickler, J. Wylie-Rosett, T. Rohan, et al., "The relation of type 2 diabetes and cancer," Diabetes Technology and Therapeutics, vol. 3, no. 2, pp. 263-274, 2001.

[9] H. Yki-Järvinen, “Thiazolidinediones," The New England Journal of Medicine, vol. 351, no. 11, pp. 1106-1118, 2004.

[10] H. J. Burstein, G. D. Demetri, E. Mueller, P. Sarraf, B. M. Spiegelman, and E. P. Winer, "Use of the peroxisome proliferator-activated receptor (PPAR) $\gamma$ ligand troglitazone as treatment for refractory breast cancer: a phase II study," Breast Cancer Research and Treatment, vol. 79, no. 3, pp. 391397, 2003.

[11] R. Butler, S. H. Mitchell, D. J. Tindall, and C. Y. F. Young, "Nonapoptotic cell death associated with S-phase arrest of prostate cancer cells via the peroxisome proliferator-activated receptor $\gamma$ ligand, 15-deoxy- $\Delta^{12,14}$-prostaglandin $\mathrm{J}_{2}$, , Cell Growth and Differentiation, vol. 11, no. 1, pp. 49-61, 2000.

[12] T.-H. Chang and E. Szabo, "Induction of differentiation and apoptosis by ligands of peroxisome proliferator-activated receptor $\gamma$ in non-small cell lung cancer," Cancer Research, vol. 60 , no. 4, pp. 1129-1138, 2000.

[13] A. P. Heaney, M. Fernando, W. H. Yong, and S. Melmed, "Functional PPAR- $\gamma$ receptor is a novel therapeutic target for ACTH-secreting pituitary adenomas," Nature Medicine, vol. 8, no. 11, pp. 1281-1287, 2002.

[14] K.-I. Inoue, Y. Kawahito, Y. Tsubouchi, et al., "Expression of peroxisome proliferator-activated receptor $\gamma$ in renal cell carcinoma and growth inhibition by its agonists," Biochemical and Biophysical Research Communications, vol. 287, no. 3, pp. 727-732, 2001.

[15] S. Kawa, T. Nikaido, H. Unno, N. Usuda, K. Nakayama, and K. Kiyosawa, "Growth inhibition and differentiation of pancreatic cancer cell lines by PPAR $y$ ligand troglitazone," Pancreas, vol. 24, no. 1, pp. 1-7, 2002.

[16] M.-Y. Li, H. Deng, J.-M. Zhao, D. Dai, and X.-Y. Tan, "Peroxisome proliferator-activated receptor gamma ligands inhibit cell growth and induce apoptosis in human liver cancer BEL-7402 cell," World Journal of Gastroenterology, vol. 9, no. 8, pp. 1683-1688, 2003.

[17] E. Mueller, M. Smith, P. Sarraf, et al., "Effects of ligand activation of peroxisome proliferator-activated receptor $\gamma$ in human prostate cancer," Proceedings of the National Academy of Sciences of the United States of America, vol. 97, no. 20, pp. 10990-10995, 2000.

[18] T. Shimada, K. Kojima, K. Yoshiura, H. Hiraishi, and A. Terano, "Characteristics of the peroxisome proliferator activated receptor $\gamma(\operatorname{PPAR} \gamma)$ ligand induced apoptosis in colon cancer cells," Gut, vol. 50, no. 5, pp. 658-664, 2002.

[19] B. Valentinis and R. Baserga, "IGF-I receptor signalling in transformation and differentiation," Molecular Pathology, vol. 54, no. 3, pp. 133-137, 2001.

[20] V. R. Sara and K. Hall, "Insulin-like growth factors and their binding proteins," Physiological Reviews, vol. 70, no. 3, pp. 591-614, 1990.

[21] A. Ullrich, J. R. Bell, and E. Y. Chen, "Human insulin receptor and its relationship to the tyrosine kinase family of oncogenes," Nature, vol. 313, no. 6005, pp. 756-761, 1985.

[22] A. Ullrich, A. Gray, A. W. Tam, et al., "Insulin-like growth factor I receptor primary structure: comparison with insulin receptor suggests structural determinants that define functional specificity," The EMBO Journal, vol. 5, no. 10, pp. 2503-2512, 1986. 
[23] H. Kato, T. N. Faria, B. Stannard, C. T. Roberts Jr., and D. LeRoith, "Essential role of tyrosine residues 1131, 1135, and 1136 of the insulin-like growth factor-I (IGF-I) receptor in IGF-I action," Molecular Endocrinology, vol. 8, no. 1, pp. 4050,1994

[24] D. E. Moller, A. Yokota, J. F. Caro, and J. S. Flier, “Tissuespecific expression of two alternatively spliced insulin receptor mRNAs in man," Molecular Endocrinology, vol. 3, no. 8, pp. 1263-1269, 1989.

[25] L. Mosthaf, K. Grako, T. J. Dull, L. Coussens, A. Ullrich, and D. A. McClain, "Functionally distinct insulin receptors generated by tissue-specific alternative splicing," The EMBO Journal, vol. 9, no. 8, pp. 2409-2413, 1990.

[26] P. Sbraccia, A. Giaccari, M. D’Adamo, et al., "Expression of the two insulin receptor isoforms is not altered in the skeletal muscle and liver of diabetic rats," Metabolism, vol. 47, no. 2, pp. 129-132, 1998.

[27] G. Pandini, F. Frasca, R. Mineo, L. Sciacca, R. Vigneri, and A. Belfiore, "Insulin/insulin-like growth factor I hybrid receptors have different biological characteristics depending on the insulin receptor isoform involved," The Journal of Biological Chemistry, vol. 277, no. 42, pp. 39684-39695, 2002.

[28] L. Sciacca, M. Prisco, A. Wu, A. Belfiore, R. Vigneri, and R. Baserga, "Signaling differences from the A and B isoforms of the insulin receptor (IR) in $32 \mathrm{D}$ cells in the presence or absence of IR substrate-1," Endocrinology, vol. 144, no. 6, pp. 2650-2658, 2003.

[29] A. Denley, E. R. Bonython, G. W. Booker, et al., "Structural determinants for high-affinity binding of insulin-like growth factor II to insulin receptor (IR)-A, the exon 11 minus isoform of the IR," Molecular Endocrinology, vol. 18, no. 10, pp. 2502-2512, 2004.

[30] R. Drakas, X. Tu, and R. Baserga, "Control of cell size through phosphorylation of upstream binding factor 1 by nuclear phosphatidylinositol 3-kinase," Proceedings of the National Academy of Sciences of the United States of America, vol. 101, no. 25, pp. 9272-9276, 2004.

[31] C. R. Kahn, "The Gordon Wilson Lecture. Lessons about the control of glucose homeostasis and the pathogenesis of diabetes from knockout mice," Transactions of the American Clinical and Climatological Association, vol. 114, pp. 125-148, 2003.

[32] J. S. Sussenbach, R. J. T. Rodenburg, W. Scheper, and P. Holthuizen, "Transcriptional and post-transcriptional regulation of the human IGF-II gene expression," Advances in Experimental Medicine and Biology, vol. 343, pp. 63-71, 1993.

[33] L. Zhang, F. Kashanchi, Q. Zhan, et al., "Regulation of insulin-like growth factor II P3 promoter by p53: a potential mechanism for tumorigenesis," Cancer Research, vol. 56, no. 6, pp. 1367-1373, 1996.

[34] N. M. Probst-Hensch, J.-M. Yuan, F. Z. Stanczyk, Y.-T. Gao, R. K. Ross, and M. C. Yu, "IGF-1, IGF-2 and IGFBP-3 in prediagnostic serum: association with colorectal cancer in a cohort of Chinese men in Shanghai," British Journal of Cancer, vol. 85, no. 11, pp. 1695-1699, 2001.

[35] C. A. Conover and D. R. Powell, "Insulin-like growth factor (IGF)-binding protein-3 blocks IGF-I-induced receptor down-regulation and cell densitization in cultured bovine fibroblasts," Endocrinology, vol. 129, no. 2, pp. 710-716, 1991.

[36] C. Schairer, D. Hill, S. R. Sturgeon, et al., "Serum concentrations of IGF-I, IGFBP-3 and c-peptide and risk of hyperplasia and cancer of the breast in postmenopausal women," International Journal of Cancer, vol. 108, no. 5, pp. 773-779, 2004.
[37] D. LeRoith and C. T. Roberts Jr., "The insulin-like growth factor system and cancer," Cancer Letters, vol. 195, no. 2, pp. 127-137, 2003.

[38] F. P. Ottensmeyer, D. R. Beniac, R. Z.-T. Luo, and C. C. Yip, "Mechanism of transmembrane signaling: insulin binding and the insulin receptor," Biochemistry, vol. 39, no. 40, pp. 12103-12112, 2000.

[39] F. Liu and R. A. Roth, "Binding of $\mathrm{SH} 2$ containing proteins to the insulin receptor: a new way for modulating insulin signalling," Molecular and Cellular Biochemistry, vol. 182, no. 1-2, pp. 73-78, 1998.

[40] M. Kanzaki and J. E. Pessin, "Signal integration and the specificity of insulin action," Cell Biochemistry and Biophysics, vol. 35, no. 2, pp. 191-209, 2001.

[41] L. S. Harrington, G. M. Findlay, and R. F. Lamb, "Restraining PI3K: mTOR signalling goes back to the membrane," Trends in Biochemical Sciences, vol. 30, no. 1, pp. 35-42, 2005.

[42] B. P. Ceresa and J. E. Pessin, "Insulin regulation of the Ras activation/inactivation cycle," Molecular and Cellular Biochemistry, vol. 182, no. 1-2, pp. 23-29, 1998.

[43] N. Hay and N. Sonenberg, "Upstream and downstream of mTOR," Genes and Development, vol. 18, no. 16, pp. 19261945, 2004.

[44] D. D. Sarbassov, S. M. Ali, and D. M. Sabatini, "Growing roles for the mTOR pathway," Current Opinion in Cell Biology, vol. 17 , no. 6, pp. 596-603, 2005.

[45] X. Wang and C. G. Proud, "The mTOR pathway in the control of protein synthesis," Physiology, vol. 21, no. 5, pp. 362-369, 2006.

[46] A. Barthel, D. Schmoll, and T. G. Unterman, "FoxO proteins in insulin action and metabolism," Trends in Endocrinology and Metabolism, vol. 16, no. 4, pp. 183-189, 2005.

[47] S. S. Myatt and E. W.-F. Lam, "The emerging roles of forkhead box (Fox) proteins in cancer," Nature Reviews Cancer, vol. 7, no. 11, pp. 847-859, 2007.

[48] J. Nakae, B.-C. Park, and D. Accili, "Insulin stimulates phosphorylation of the forkhead transcription factor FKHR on serine 253 through a wortmannin-sensitive pathway," The Journal of Biological Chemistry, vol. 274, no. 23, pp. 1598215985, 1999.

[49] Y. Zou, W. B. Tsai, C. J. Cheng, et al., "Forkhead box transcription factor FOXO3a suppresses estrogen-dependent breast cancer cell proliferation and tumorigenesis," Breast Cancer Research, vol. 10, no. 1, article R21, 2008.

[50] B. M. T. Burgering and G. J. P. L. Kops, "Cell cycle and death control: long live forkheads," Trends in Biochemical Sciences, vol. 27, no. 7, pp. 352-360, 2002.

[51] T. Kino, M. U. De Martino, E. Charmandari, T. Ichijo, T. Outas, and G. P. Chrousos, "HIV-1 accessory protein Vpr inhibits the effect of insulin on the Foxo subfamily of forkhead transcription factors by interfering with their binding to 14-3-3 proteins: potential clinical implications regarding the insulin resistance of HIV-1-infected patients," Diabetes, vol. 54, no. 1, pp. 23-31, 2005.

[52] G. J. P. L. Kops, N. D. de Ruiter, A. M. M. De Vries-Smits, D. R. Powell, J. L. Bos, and B. M. Th. Burgering, "Direct control of the forkhead transcription faotor AFX by protein kinase B," Nature, vol. 398, no. 6728, pp. 630-634, 1999.

[53] V. Stambolic, A. Suzuki, J. L. de la Pompa, et al., "Negative regulation of PKB/Akt-dependent cell survival by the tumor suppressor PTEN," Cell, vol. 95, no. 1, pp. 29-39, 1998.

[54] L. Simpson and R. Parsons, "PTEN: life as a tumor suppressor," Experimental Cell Research, vol. 264, no. 1, pp. 29-41, 2001. 
[55] Y. Kaburagi, R. Yamamoto-Honda, K. Tobe, et al., "The role of the NPXY motif in the insulin receptor in tyrosine phosphorylation of insulin receptor substrate-1 and Shc," Endocrinology, vol. 136, no. 8, pp. 3437-3443, 1995.

[56] K. Kondoh, S. Torii, and E. Nishida, "Control of MAP kinase signaling to the nucleus," Chromosoma, vol. 114, no. 2, pp. 86-91, 2005.

[57] A. Brunet, D. Roux, P. Lenormand, S. Dowd, S. Keyse, and J. Pouysségur, "Nuclear translocation of p42/p44 mitogenactivated protein kinase is required for growth factorinduced gene expression and cell cycle entry," The EMBO Journal, vol. 18, no. 3, pp. 664-674, 1999.

[58] P. P. Roux and J. Blenis, "ERK and p38 MAPK-activated protein kinases: a family of protein kinases with diverse biological functions," Microbiology and Molecular Biology Reviews, vol. 68, no. 2, pp. 320-344, 2004.

[59] J. M. Chan, M. J. Stampfer, E. Giovannucci, et al., "Plasma insulin-like growth factor-I and prostate cancer risk: a prospective study," Science, vol. 279, no. 5350, pp. 563-566, 1998.

[60] S. E. Hankinson, W. C. Willett, G. A. Colditz, et al., "Circulating concentrations of insulin-like growth factor-I and risk of breast cancer," The Lancet, vol. 351, no. 9113, pp. 1393-1396, 1998.

[61] J. Ma, M. N. Pollak, E. Giovannucci, et al., "Prospective study of colorectal cancer risk in men and plasma levels of insulin-like growth factor (IGF)-I and IGF-binding protein3," Journal of the National Cancer Institute, vol. 91, no. 7, pp. 620-625, 1999.

[62] H. Yu, M. R. Spitz, J. Mistry, J. Gu, W. K. Hong, and X. Wu, "Plasma levels of insulin-like growth factor-I and lung cancer risk: a case-control analysis," Journal of the National Cancer Institute, vol. 91, no. 2, pp. 151-156, 1999.

[63] H. Zhao, H. B. Grossman, M. R. Spitz, S. P. Lerner, K. Zhang, and $\mathrm{X}$. Wu, "Plasma levels of insulin-like growth factor-1 and binding protein-3, and their association with bladder cancer risk," The Journal of Urology, vol. 169, no. 2, pp. 714-717, 2003.

[64] S. Loeper and S. Ezzat, "Acromegaly: re-thinking the cancer risk," Reviews in Endocrine and Metabolic Disorders, vol. 9, no. 1, pp. 41-58, 2008.

[65] W. R. Bruce, T. M. S. Wolever, and A. Giacca, "Mechanisms linking diet and colorectal cancer: the possible role of insulin resistance," Nutrition and Cancer, vol. 37, no. 1, pp. 19-26, 2000.

[66] P. J. Goodwin, M. Ennis, K. I. Pritchard, et al., "Fasting insulin and outcome in early-stage breast cancer: results of a prospective cohort study," Journal of Clinical Oncology, vol. 20, no. 1, pp. 42-51, 2002.

[67] R. A. Jones, C. I. Campbell, E. J. Gunther, et al., "Transgenic overexpression of IGF-IR disrupts mammary ductal morphogenesis and induces tumor formation," Oncogene, vol. 26, no. 11, pp. 1636-1644, 2007.

[68] A. Ouban, P. Muraca, T. Yeatman, and D. Coppola, "Expression and distribution of insulin-like growth factor- 1 receptor in human carcinomas," Human Pathology, vol. 34, no. 8, pp. 803-808, 2003.

[69] V. Papa, V. Pezzino, A. Costantino, et al., "Elevated insulin receptor content in human breast cancer," The Journal of Biological Chemistry, vol. 86, no. 5, pp. 1503-1510, 1990.

[70] L. Sciacca, A. Costantino, G. Pandini, et al., "Insulin receptor activation by IGF-II in breast cancers: evidence for a new autocrine/paracrine mechanism," Oncogene, vol. 18, no. 15, pp. 2471-2479, 1999.
[71] F. Frasca, G. Pandini, P. Scalia, et al., "Insulin receptor isoform A, a newly recognized, high-affinity insulin-like growth factor II receptor in fetal and cancer cells," Molecular and Cellular Biology, vol. 19, no. 5, pp. 3278-3288, 1999.

[72] G. Pandini, R. Vigneri, A. Costantino, et al., "Insulin and insulin-like growth factor-I (IGF-I) receptor overexpression in breast cancers leads to insulin/IGF-I hybrid receptor overexpression: evidence for a second mechanism of IGF-I signaling," Clinical Cancer Research, vol. 5, no. 7, pp. 19351944, 1999.

[73] C. L. Arteaga and C. K. Osborne, "Growth inhibition of human breast cancer cells in vitro with an antibody against the type I somatomedin receptor," Cancer Research, vol. 49, no. 22, pp. 6237-6241, 1989.

[74] K. J. Cullen, A. Allison, I. Martire, M. Ellis, and C. Singer, "Insulin-like growth factor expression in breast cancer epithelium and stroma," Breast Cancer Research and Treatment, vol. 22, no. 1, pp. 21-29, 1992.

[75] P. Bates, R. Fisher, A. Ward, L. Richardson, D. J. Hill, and C. F. Graham, "Mammary cancer in transgenic mice expressing insulin-like growth factor II (IGF-II)," British Journal of Cancer, vol. 72, no. 5, pp. 1189-1193, 1995.

[76] D. L. Hadsell, K. L. Murphy, S. G. Bonnette, N. Reece, R. Laucirica, and J. M. Rosen, "Cooperative interaction between mutant p53 and des(1-3)IGF-I accelerates mammary tumorigenesis," Oncogene, vol. 19, no. 7, pp. 889-898, 2000.

[77] R. A. Moorehead, J. E. Fata, M. B. Johnson, and R. Khokha, "Inhibition of mammary epithelial apoptosis and sustained phosphorylation of Akt/PKB in MMTV-IGF-II transgenic mice," Cell Death and Differentiation, vol. 8, no. 1, pp. 16-29, 2001.

[78] S. Neuenschwander, A. Schwartz, T. L. Wood, C. T. Roberts Jr., L. Henninghausen, and D. LeRoith, "Involution of the lactating mammary gland is inhibited by the IGF system in a transgenic mouse model," The Journal of Biological Chemistry, vol. 97, no. 10, pp. 2225-2232, 1996.

[79] R. O'Connor, C. Fennelly, and D. Krause, "Regulation of survival signals from the insulin-like growth factor-I receptor," Biochemical Society Transactions, vol. 28, no. 2, pp. 47-51, 2000.

[80] S. Coats, W. M. Flanagan, J. Nourse, and J. M. Roberts, "Requirement of p27Kip1 for restriction point control of the fibroblast cell cycle," Science, vol. 272, no. 5263, pp. 877-880, 1996.

[81] J. Dupont, S. E. Dunn, J. C. Barrett, and D. LeRoith, "Microarray analysis and identification of novel molecules involved in insulin-like growth factor-1 receptor signaling and gene expression," Recent Progress in Hormone Research, vol. 58, pp. 325-342, 2003.

[82] P. Stawowy, H. Kallisch, A. Kilimnik, et al., "Proprotein convertases regulate insulin-like growth factor 1-induced membrane-type 1 matrix metalloproteinase in VSMCs via endoproteolytic activation of the insulin-like growth factor-1 receptor," Biochemical and Biophysical Research Communications, vol. 321, no. 3, pp. 531-538, 2004.

[83] X. Zhang, M. Lin, K. L. Van Golen, K. Yoshioka, K. Itoh, and D. Yee, "Multiple signaling pathways are activated during insulin-like growth factor-I (IGF-I) stimulated breast cancer cell migration," Breast Cancer Research and Treatment, vol. 93, no. 2, pp. 159-168, 2005.

[84] R. Baserga, F. Peruzzi, and K. Reiss, "The IGF-1 receptor in cancer biology," International Journal of Cancer, vol. 107, no. 6, pp. 873-877, 2003. 
[85] M. Kaleko, W. J. Rutter, and A. D. Miller, "Overexpression of the human insulinlike growth factor I receptor promotes ligand-dependent neoplastic transformation," Molecular and Cellular Biology, vol. 10, no. 2, pp. 464-473, 1990.

[86] J.-L. Liu, V. A. Blakesley, J. S. Gutkind, and D. LeRoith, "The constitutively active mutant $\mathrm{G}_{\alpha 13}$ transforms mouse fibroblast cells deficient in insulin-like growth factor-I receptor," The Journal of Biological Chemistry, vol. 272, no. 47, pp. 29438-29441, 1997.

[87] C. Sell, G. Dumenil, C. Deveaud, et al., "Effect of a null mutation of the insulin-like growth factor I receptor gene on growth and transformation of mouse embryo fibroblasts," Molecular and Cellular Biology, vol. 14, no. 6, pp. 3604-3612, 1994.

[88] F. Giorgino, A. Belfiore, G. Milazzo, et al., "Overexpression of insulin receptors in fibroblast and ovary cells induces a ligand-mediated transformed phenotype," Molecular Endocrinology, vol. 5, no. 3, pp. 452-459, 1991.

[89] C. C. Mastick, H. Kato, C. T. Roberts Jr., D. LeRoith, and A. R. Saltiel, "Insulin and insulin-like growth factor-I receptors similarly stimulate deoxyribonucleic acid synthesis despite differences in cellular protein tyrosine phosphorylation," Endocrinology, vol. 135, no. 1, pp. 214-222, 1994.

[90] G. Milazzo, F. Giorgino, G. Damante, et al., "Insulin receptor expression and function in human breast cancer cell lines," Cancer Research, vol. 52, no. 14, pp. 3924-3930, 1992.

[91] G. Pillemer, H. Lugasi-Evgi, G. Scharovsky, and D. Naor, "Insulin dependence of murine lymphoid T-cell leukemia," International Journal of Cancer, vol. 50, no. 1, pp. 80-85, 1992.

[92] A.-M. Benoliel, B. Kahn-Perles, J. Imbert, and P. Verrando, "Insulin stimulates haptotactic migration of human epidermal keratinocytes through activation of NF- $\kappa \mathrm{B}$ transcription factor," Journal of Cell Science, vol. 110, part 17, pp. 20892097, 1997.

[93] L. Sciacca, R. Mineo, G. Pandini, A. Murabito, R. Vigneri, and A. Belfiore, "In IGF-I receptor-deficient leiomyosarcoma cells autocrine IGF-II induces cell invasion and protection from apoptosis via the insulin receptor isoform A," Oncogene, vol. 21, no. 54, pp. 8240-8250, 2002.

[94] A. J. Casa, R. K. Dearth, B. C. Litzenburger, A. V. Lee, and X. Cui, "The type I insulin-like growth factor receptor pathway: a key player in cancer therapeutic resistance," Frontiers in Bioscience, vol. 13, no. 9, pp. 3273-3287, 2008.

[95] D. Yu, H. Watanabe, H. Shibuya, and M. Miura, "Redundancy of radioresistant signaling pathways originating from insulin-like growth factor I receptor," The Journal of Biological Chemistry, vol. 278, no. 9, pp. 6702-6709, 2003.

[96] S. Theocharis, A. Margeli, P. Vielh, and G. Kouraklis, "Peroxisome proliferator-activated receptor- $\gamma$ ligands as cellcycle modulators," Cancer Treatment Reviews, vol. 30, no. 6, pp. 545-554, 2004.

[97] L. Michalik, B. Desvergne, and W. Wahli, "Peroxisomeproliferator-activated receptors and cancers: complex stories," Nature Reviews Cancer, vol. 4, no. 1, pp. 61-70, 2004.

[98] J. Zhou, K. M. Wilson, and J. D. Medh, "Genetic analysis of four novel peroxisome proliferator activated receptor- $\gamma$ splice variants in monkey macrophages," Biochemical and Biophysical Research Communications, vol. 293, no. 1, pp. 274-283, 2002.

[99] J. C. Corton, S. P. Anderson, and A. Stauber, "Central role of peroxisome proliferator-activated receptors in the actions of peroxisome proliferators," Annual Review of Pharmacology and Toxicology, vol. 40, pp. 491-518, 2000.
[100] Y. Kodera, K.-I. Takeyama, A. Murayama, M. Suzawa, Y. Masuhiro, and S. Kato, "Ligand type-specific interactions of peroxisome proliferator-activated receptor $\gamma$ with transcriptional coactivators," The Journal of Biological Chemistry, vol. 275, no. 43, pp. 33201-33204, 2000.

[101] W. Yang, C. Rachez, and L. P. Freedman, "Discrete roles for peroxisome proliferator-activated receptor $\gamma$ and retinoid $\mathrm{X}$ receptor in recruiting nuclear receptor coactivators," Molecular and Cellular Biology, vol. 20, no. 21, pp. 8008-8017, 2000.

[102] S. A. Kliewer, B. M. Forman, B. Blumberg, et al., "Differential expression and activation of a family of murine peroxisome proliferator-activated receptors," Proceedings of the National Academy of Sciences of the United States of America, vol. 91, no. 15, pp. 7355-7359, 1994.

[103] Y. Yokoyama, B. Xin, T. Shigeto, et al., "Clofibric acid, a peroxisome proliferator-activated receptor $\alpha$ ligand, inhibits growth of human ovarian cancer," Molecular Cancer Therapeutics, vol. 6, no. 4, pp. 1379-1386, 2007.

[104] H. Keller, C. Dreyer, J. Medin, A. Mahfoudi, K. Ozato, and W. Wahli, "Fatty acids and retinoids control lipid metabolism through activation of peroxisome proliferatoractivated receptor-retinoid X receptor heterodimers," Proceedings of the National Academy of Sciences of the United States of America, vol. 90, no. 6, pp. 2160-2164, 1993.

[105] H. Keller, A. Mahfoudi, C. Dreyer, et al., "Peroxisome proliferator-activated receptors and lipid metabolism," Annals of the New York Academy of Sciences, vol. 684, pp. 157173, 1993.

[106] J. L. Hatton and L. D. Yee, "Clinical use of PPAR $\gamma$ ligands in cancer," PPAR Research, vol. 2008, Article ID 159415, 13 pages, 2008.

[107] C. E. Clay, A. M. Namen, G.-I. Atsumi, et al., "Influence of $\mathrm{J}$ series prostaglandins on apoptosis and tumorigenesis of breast cancer cells," Carcinogenesis, vol. 20, no. 10, pp. 19051911, 1999.

[108] M. Li, T. W. Lee, A. P. C. Yim, T. S. K. Mok, and G. G. Chen, "Apoptosis induced by troglitazone is both peroxisome proliterator-activated receptor- $\gamma$ - and ERK-dependent in human non-small lung cancer cells," Journal of Cellular Physiology, vol. 209, no. 2, pp. 428-438, 2006.

[109] A. Aiello, G. Pandini, F. Frasca, et al., "Peroxisomal proliferator-activated receptor- $\gamma$ agonists induce partial reversion of epithelial-mesenchymal transition in anaplastic thyroid cancer cells," Endocrinology, vol. 147, no. 9, pp. 44634475, 2006.

[110] J.-R. Weng, C.-Y. Chen, J. J. Pinzone, M. D. Ringel, and C.S. Chen, "Beyond peroxisome proliferator-activated receptor $\gamma$ signaling: the multi-facets of the antitumor effect of thiazolidinediones," Endocrine-Related Cancer, vol. 13, no. 2, pp. 401-413, 2006.

[111] F. Chen and L. E. Harrison, "Ciglitazone-induced cellular anti-proliferation increases p27 kip 1 protein levels through both increased transcriptional activity and inhibition of proteasome degradation," Cellular Signalling, vol. 17, no. 7, pp. 809-816, 2005.

[112] E. A. Musgrove, C. S. L. Lee, M. F. Buckley, and R. L. Sutherland, "Cyclin D1 induction in breast cancer cells shortens G1 and is sufficient for cells arrested in G1 to complete the cell cycle," Proceedings of the National Academy of Sciences of the United States of America, vol. 91, no. 17, pp. 8022-8026, 1994. 
[113] S. Kawakami, G. Arai, T. Hayashi, et al., "PPAR $\gamma$ ligands suppress proliferation of human urothelial basal cells in vitro," Journal of Cellular Physiology, vol. 191, no. 3, pp. 310319, 2002.

[114] F.-G. Yang, Z.-W. Zhang, D.-Q. Xin, et al., "Peroxisome proliferator-activated receptor $\gamma$ ligands induce cell cycle arrest and apoptosis in human renal carcinoma cell lines," Acta Pharmacologica Sinica, vol. 26, no. 6, pp. 753-761, 2005.

[115] E. Mueller, P. Sarraf, P. Tontonoz, et al., "Terminal differentiation of human breast cancer through PPAR $\gamma$," Molecular Cell, vol. 1, no. 3, pp. 465-470, 1998.

[116] W. Zhang, H. Zhang, and L. Xing, "Influence of ciglitazone on A549 cells growth in vitro and in vivo and mechanism," Journal of Huazhong University of Science and Technology. Medical Sciences, vol. 26, no. 1, pp. 36-39, 2006.

[117] T. Ohta, A. Elnemr, M. Yamamoto, et al., "Thiazolidinedione, a peroxisome proliferator-activated receptor-gamma ligand, modulates the E-cadherin/beta-catenin system in a human pancreatic cancer cell line, BxPC-3," International Journal of Oncology, vol. 21, no. 1, pp. 37-42, 2002.

[118] G. Piwien-Pilipuk, D. Van Mater, S. E. Ross, O. A. MacDougald, and J. Schwartz, "Growth hormone regulates phosphorylation and function of CCAAT/enhancer-binding protein $\beta$ by modulating Akt and glycogen synthase kinase3," The Journal of Biological Chemistry, vol. 276, no. 22, pp. 19664-19671, 2001.

[119] M. Moldes, Y. Zuo, R. F. Morrison, et al., "Peroxisomeproliferator-activated receptor $\gamma$ suppresses $\mathrm{Wnt} / \beta$-catenin signalling during adipogenesis," Biochemical Journal, vol. 376, no. 3, pp. 607-613, 2003.

[120] J. Liu, H. Wang, Y. Zuo, and S. R. Farmer, "Functional interaction between peroxisome proliferator-activated receptor $\gamma$ and $\beta$-catenin," Molecular and Cellular Biology, vol. 26, no. 15, pp. 5827-5837, 2006.

[121] D. Lu, H. B. Cottam, M. Corr, and D. A. Carson, "Repression of $\beta$-catenin function in malignant cells by nonsteroidal antiinflammatory drugs," Proceedings of the National Academy of Sciences of the United States of America, vol. 102, no. 51, pp. 18567-18571, 2005.

[122] S. E. Ross, N. Hemati, K. A. Longo, et al., "Inhibition of adipogenesis by Wnt signaling," Science, vol. 289, no. 5481, pp. 950-953, 2000.

[123] D. Panigrahy, S. Singer, L. Q. Shen, et al., "PPAR $\gamma$ ligands inhibit primary tumor growth and metastasis by inhibiting angiogenesis," The Journal of Clinical Investigation, vol. 110, no. 7, pp. 923-932, 2002.

[124] X. Xin, S. Yang, J. Kowalski, and M. E. Gerritsen, "Peroxisome proliferator-activated receptor $\gamma$ ligands are potent inhibitors of angiogenesis in vitro and in vivo," The Journal of Biological Chemistry, vol. 274, no. 13, pp. 9116-9121, 1999.

[125] S. Z. Duan, C. Y. Ivashchenko, M. G. Usher, and R. M. Mortensen, "PPAR-gamma in the cardiovascular system," PPAR Research, vol. 2008, Article ID 745804, 10 pages, 2008.

[126] M. J. Reginato, S. L. Krakow, S. T. Bailey, and M. A. Lazar, "Prostaglandins promote and block adipogenesis through opposing effects on peroxisome proliferator-activated receptor $\gamma$," The Journal of Biological Chemistry, vol. 273, no. 4, pp. 1855-1858, 1998.

[127] L. C. Hsi, L. Wilson, J. Nixon, and T. E. Eling, "15lipoxygenase-1 metabolites down-regulate peroxisome proliferator-activated receptor $\gamma$ via the MAPK signaling pathway," The Journal of Biological Chemistry, vol. 276, no. 37, pp. 34545-34552, 2001.
[128] M. Aouadi, K. Laurent, M. Prot, Y. Le Marchand-Brustel, B. Binétruy, and F. Bost, "Inhibition of p38MAPK increases adipogenesis from embryonic to adult stages," Diabetes, vol. 55, no. 2, pp. 281-289, 2006.

[129] Z. E. Floyd and J. M. Stephens, "Interferon- $\boldsymbol{\gamma}$-mediated activation and ubiquitin-proteasome-dependent degradation of PPAR $y$ in adipocytes," The Journal of Biological Chemistry, vol. 277, no. 6, pp. 4062-4068, 2002.

[130] M. Hedvat, A. Jain, D. A. Carson, et al., "Inhibition of HER-kinase activation prevents ERK-mediated degradation of PPARy," Cancer Cell, vol. 5, no. 6, pp. 565-574, 2004.

[131] E. Burgermeister, D. Chuderland, T. Hanoch, M. Meyer, M. Liscovitch, and R. Seger, "Interaction with MEK causes nuclear export and downregulation of peroxisome proliferator-activated receptor $\gamma$," Molecular and Cellular Biology, vol. 27, no. 3, pp. 803-817, 2007.

[132] A. J. Chang, D. H. Song, and M. M. Wolfe, "Attenuation of peroxisome proliferator-activated receptor $\gamma(\operatorname{PPAR} \gamma)$ mediates gastrin-stimulated colorectal cancer cell proliferation," The Journal of Biological Chemistry, vol. 281, no. 21, pp. 14700-14710, 2006.

[133] P. Mukunyadzi, L. Ai, D. Portilla, E. L. Barnes, and C.-Y. Fan, "Expression of peroxisome proliferator-activated receptor gamma in salivary duct carcinoma: immunohistochemical analysis of 15 cases," Modern Pathology, vol. 16, no. 12, pp. 1218-1223, 2003.

[134] I. Papadaki, E. Mylona, I. Giannopoulou, S. Markaki, A. Keramopoulos, and L. Nakopoulou, "PPAR $\gamma$ expression in breast cancer: clinical value and correlation with ER $\beta$," Histopathology, vol. 46, no. 1, pp. 37-42, 2005.

[135] H. J. Kim, J. Y. Hwang, H. J. Kim, et al., "Expression of a peroxisome proliferator-activated receptor gamma 1 splice variant that was identified in human lung cancers suppresses cell death induced by cisplatin and oxidative stress," Clinical Cancer Research, vol. 13, no. 9, pp. 2577-2583, 2007.

[136] S. Nomura, A. Nakajima, S. Ishimine, N. Matsuhashi, T. Kadowaki, and M. Kaminishi, "Differential expression of peroxisome proliferator-activated receptor in histologically different human gastric cancer tissues," Journal of Experimental and Clinical Cancer Research, vol. 25, no. 3, pp. 443-448, 2006.

[137] W. Motomura, T. Okumura, N. Takahashi, T. Obara, and Y. Kohgo, "Activation of peroxisome proliferator-activated receptor $\gamma$ by troglitazone inhibits cell growth through the increase of p27(Kip1) in human pancreatic carcinoma cells," Cancer Research, vol. 60, no. 19, pp. 5558-5564, 2000.

[138] A. Sugimura, Y. Kiriyama, H. Nochi, et al., "Troglitazone suppresses cell growth of myeloid leukemia cell lines by induction of p21WAF1/CIP1 cyclin-dependent kinase inhibitor," Biochemical and Biophysical Research Communications, vol. 261, no. 3, pp. 833-837, 1999.

[139] A. M. Lennon, M. Ramaugé, A. Dessouroux, and M. Pierre, "MAP kinase cascades are activated in astrocytes and preadipocytes by 15 -deoxy- $\Delta^{12-14}$-prostaglandin $\mathrm{J}_{2}$ and the thiazolidinedione ciglitazone through peroxisome proliferator activator receptor gamma-independent mechanisms involving reactive oxygenated species," The Journal of Biological Chemistry, vol. 277, no. 33, pp. 29681-29685, 2002.

[140] K. M. Patel, K. L. Wright, P. Whittaker, P. Chakravarty, M. L. Watson, and S. G. Ward, "Differential modulation of COX2 expression in A549 airway epithelial cells by structurally distinct PPAR $\gamma$ agonists: evidence for disparate functional effects which are independent of NF- $\kappa \mathrm{B}$ and PPAR $\gamma$," Cellular Signalling, vol. 17, no. 9, pp. 1098-1110, 2005. 
[141] M. Li, T. W. Lee, T. S. K. Mok, T. D. Warner, A. P. C. Yim, and G. G. Chen, "Activation of peroxisome proliferator-activated receptor- $\gamma$ by troglitazone (TGZ) inhibits human lung cell growth," Journal of Cellular Biochemistry, vol. 96, no. 4, pp. 760-774, 2005.

[142] K.-H. Kim, Y. S. Cho, J.-M. Park, S.-O. Yoon, K.-W. Kim, and A.-S. Chung, "Pro-MMP-2 activation by the PPAR $\gamma$ agonist, ciglitazone, induces cell invasion through the generation of ROS and the activation of ERK," FEBS Letters, vol. 581, no. 17, pp. 3303-3310, 2007.

[143] E.-H. Kim, H.-K. Na, and Y.-J. Surh, "Upregulation of VEGF by 15 -deoxy- $\Delta^{12,14}$-prostaglandin $\mathrm{J}_{2}$ via heme oxygenase-1 and ERK1/2 signaling in MCF-7 cells," Annals of the New York Academy of Sciences, vol. 1090, pp. 375-384, 2006.

[144] L.-Q. Cao, X.-L. Chen, Q. Wang, et al., "Upregulation of PTEN involved in rosiglitazone-induced apoptosis in human hepatocellular carcinoma cells," Acta Pharmacologica Sinica, vol. 28 , no. 6, pp. 879-887, 2007.

[145] W. Zhang, N. Wu, Z. Li, L. Wang, J. Jin, and X.-L. Zha, "PPAR $\gamma$ activator rosiglitazone inhibits cell migration via upregulation of PTEN in human hepatocarcinoma cell line BEL-7404," Cancer Biology and Therapy, vol. 5, no. 8, pp. 1008-1014, 2006.

[146] L. Patel, I. Pass, P. Coxon, C. P. Downes, S. A. Smith, and C. H. Macphee, "Tumor suppressor and anti-inflammatory actions of PPAR $\gamma$ agonists are mediated via upregulation of PTEN," Current Biology, vol. 11, no. 10, pp. 764-768, 2001.

[147] S. Han and J. Roman, "Rosiglitazone suppresses human lung carcinoma cell growth through PPAR $\gamma$-dependent and PPAR $\gamma$-independent signal pathways," Molecular Cancer Therapeutics, vol. 5, no. 2, pp. 430-437, 2006.

[148] S. Y. Lee, G. Y. Hur, K. H. Jung, et al., "PPAR- $\gamma$ agonist increase gefitinib's antitumor activity through PTEN expression," Lung Cancer, vol. 51, no. 3, pp. 297-301, 2006.

[149] B. Farrow and B. M. Evers, "Activation of PPAR $\gamma$ increases PTEN expression in pancreatic cancer cells," Biochemical and Biophysical Research Communications, vol. 301, no. 1, pp. 5053, 2003.

[150] D.-H. Cho, J. C. Yoon, A. J. Sangmee, et al., "Troglitazone acutely inhibits protein synthesis in endothelial cells via a novel mechanism involving protein phosphatase 2Adependent p70 S6 kinase inhibition," American Journal of Physiology, vol. 291, no. 2, pp. C317-C326, 2006.

[151] G. He, Y. M. Sung, J. DiGiovanni, and S. M. Fischer, "Thiazolidinediones inhibit insulin-like growth factor-I-induced activation of p70S6 kinase and suppress insulin-like growth factor-I tumor-promoting activity," Cancer Research, vol. 66, no. 3, pp. 1873-1879, 2006.

[152] A. S. Dhillon, S. Hagan, O. Rath, and W. Kolch, "MAP kinase signalling pathways in cancer," Oncogene, vol. 26, no. 22, pp. 3279-3290, 2007.

[153] J. S. Sebolt-Leopold and R. Herrera, "Targeting the mitogenactivated protein kinase cascade to treat cancer," Nature Reviews Cancer, vol. 4, no. 12, pp. 937-947, 2004.

[154] C. Wellbrock, M. Karasarides, and R. Marais, "The RAF proteins take centre stage," Nature Reviews Molecular Cell Biology, vol. 5, no. 11, pp. 875-885, 2004.

[155] R. Hoshino, Y. Chatani, T. Yamori, et al., "Constitutive activation of the $41-/ 43-\mathrm{kDa}$ mitogen-activated protein kinase signaling pathway in human tumors," Oncogene, vol. 18, no. 3, pp. 813-822, 1999.

[156] H. S. Camp and S. R. Tafuri, "Regulation of peroxisome proliferator-activated receptor $\gamma$ activity by mitogenactivated protein kinase," The Journal of Biological Chemistry, vol. 272, no. 16, pp. 10811-10816, 1997.
[157] B. Zhang, J. Berger, G. Zhou, et al., "Insulin- and mitogenactivated protein kinase-mediated phosphorylation and activation of peroxisome proliferator-activated receptor $\gamma$," The Journal of Biological Chemistry, vol. 271, no. 50, pp. 3177131774, 1996.

[158] C. Diradourian, J. Girard, and J.-P. Pégorier, "Phosphorylation of PPARs: from molecular characterization to physiological relevance," Biochimie, vol. 87, no. 1, pp. 33-38, 2005.

[159] M. Adams, M. J. Reginato, D. Shao, M. A. Lazar, and V. K. Chatterjee, "Transcriptional activation by peroxisome proliferator-activated receptor $\gamma$ is inhibited by phosphorylation at a consensus mitogen-activated protein kinase site," The Journal of Biological Chemistry, vol. 272, no. 8, pp. 51285132, 1997.

[160] E. Hu, J. B. Kim, P. Sarraf, and B. M. Spiegelman, "Inhibition of adipogenesis through MAP kinase-mediated phosphorylation of PPAR $\gamma$," Science, vol. 274, no. 5295, pp. 2100-2103, 1996.

[161] K. Schoonjans, G. Martin, B. Staels, and J. Auwerx, "Peroxisome proliferator-activated receptors, orphans with ligands and functions," Current Opinion in Lipidology, vol. 8, no. 3, pp. 159-166, 1997.

[162] G. Lazennec, L. Canaple, D. Saugy, and W. Wahli, "Activation of peroxisome proliferator-activated receptors (PPARs) by their ligands and protein kinase A activators," Molecular Endocrinology, vol. 14, no. 12, pp. 1962-1975, 2000.

[163] D. Shao, S. M. Rangwala, S. T. Bailey, S. L. Krakow, M. J. Reginato, and M. A. Lazar, "Interdomain communication regulating ligand binding by PPAR- $\gamma$," Nature, vol. 396, no. 6709, pp. 377-380, 1998.

[164] S. Hauser, G. Adelmant, P. Sarraf, H. M. Wright, E. Mueller, and B. M. Spiegelman, "Degradation of the peroxisome proliferator-activated receptor $\gamma$ is linked to liganddependent activation," The Journal of Biological Chemistry, vol. 275, no. 24, pp. 18527-18533, 2000.

[165] C. K. Sung, H. She, S. Xiong, and H. Tsukamoto, “Tumor necrosis factor- $\alpha$ inhibits peroxisome proliferator-activated receptor $\gamma$ activity at a posttranslational level in hepatic stellate cells," American Journal of Physiology, vol. 286, no. 5, pp. G722-G729, 2004.

[166] T. Okura, M. Nakamura, Y. Takata, S. Watanabe, Y. Kitami, and K. Hiwada, "Troglitazone induces apoptosis via the p53 and Gadd45 pathway in vascular smooth muscle cells," European Journal of Pharmacology, vol. 407, no. 3, pp. 227$235,2000$.

[167] R. Scatena, P. Bottoni, G. E. Martorana, et al., "Mitochondrial respiratory chain dysfunction, a non-receptormediated effect of synthetic PPAR-ligands: biochemical and pharmacological implications," Biochemical and Biophysical Research Communications, vol. 319, no. 3, pp. 967-973, 2004.

[168] K. Hashimoto, B. J. Farrow, and B. M. Evers, "Activation and role of MAP kinases in 15d-PGJ2-induced apoptosis in the human pancreatic cancer cell line MIA PaCa-2," Pancreas, vol. 28, no. 2, pp. 153-159, 2004.

[169] Z.-Z. Shan, K. Masuko-Hongo, S.-M. Dai, H. Nakamura, T. Kato, and K. Nishioka, "A potential role of 15-deoxy$\Delta^{12,14}$-prostaglandin $\mathrm{J}_{2}$ for induction of human articular chondrocyte apoptosis in arthritis," The Journal of Biological Chemistry, vol. 279, no. 36, pp. 37939-37950, 2004.

[170] J.-A. Kim, K.-S. Park, H.-I. Kim, et al., “Troglitazone activates p21Cip/WAF1 through the ERK pathway in HCT15 human colorectal cancer cells," Cancer Letters, vol. 179, no. 2, pp. 185-195, 2002. 
[171] S. J. Baek, L. C. Wilson, L. C. Hsi, and T. E. Eling, "Troglitazone, a peroxisome proliferator-activated receptor $\gamma(\operatorname{PPAR} \gamma)$ ligand, selectively induces the early growth response- 1 gene independently of PPAR $y$ : a novel mechanism for its antitumorigenic activity," The Journal of Biological Chemistry, vol. 278, no. 8, pp. 5845-5853, 2003.

[172] K. Takeda, T. Ichiki, T. Tokunou, N. Ino, and A. Takeshita, "15-deoxy- $\Delta^{12,14}$-prostaglandin $\mathrm{J}_{2}$ and thiazolidinediones activate the MEK/ERK pathway through phosphatidylinositol 3-kinase in vascular smooth muscle cells," The Journal of Biological Chemistry, vol. 276, no. 52, pp. 48950-48955, 2001.

[173] C. Giulia, L. Adriana, P. Elisabetta, et al., "Rosiglitazone inhibits adrenocortical cancer cell proliferation by interfering with the IGF-IR intracellular signaling," PPAR Research, vol. 2008, Article ID 904041, 11 pages, 2008.

[174] M. A. Aldred, M. E. Ginn-Pease, C. D. Morrison, et al., "Caveolin-1 and caveolin-2, together with three bone morphogenetic protein-related genes, may encode novel tumor suppressors down-regulated in sporadic follicular thyroid carcinogenesis," Cancer Research, vol. 63, no. 11, pp. 28642871, 2003.

[175] F. Vazquez, S. Ramaswamy, N. Nakamura, and W. R. Sellers, "Phosphorylation of the PTEN tail regulates protein stability and function," Molecular and Cellular Biology, vol. 20, no. 14, pp. 5010-5018, 2000.

[176] K. A. Waite and C. Eng, "BMP2 exposure results in decreased PTEN protein degradation and increased PTEN levels," Human Molecular Genetics, vol. 12, no. 6, pp. 679-684, 2003.

[177] M.-A. Bjornsti and P. J. Houghton, "The TOR pathway: a target for cancer therapy," Nature Reviews Cancer, vol. 4, no. 5, pp. 335-348, 2004.

[178] K. E. O’Reilly, F. Rojo, Q.-B. She, et al., "mTOR inhibition induces upstream receptor tyrosine kinase signaling and activates Akt," Cancer Research, vol. 66, no. 3, pp. 1500-1508, 2006.

[179] Z. Luo, A. K. Saha, X. Xiang, and N. B. Ruderman, "AMPK, the metabolic syndrome and cancer," Trends in Pharmacological Sciences, vol. 26, no. 2, pp. 69-76, 2005.

[180] K. Inoki, T. Zhu, and K.-L. Guan, "TSC2 mediates cellular energy response to control cell growth and survival," Cell, vol. 115, no. 5, pp. 577-590, 2003.

[181] N. Kimura, C. Tokunaga, S. Dalal, et al., "A possible linkage between AMP-activated protein kinase (AMPK) and mammalian target of rapamycin (mTOR) signalling pathway," Genes to Cells, vol. 8, no. 1, pp. 65-79, 2003.

[182] X. Xiang, A. K. Saha, R. Wen, N. B. Ruderman, and Z. Luo, "AMP-activated protein kinase activators can inhibit the growth of prostate cancer cells by multiple mechanisms," Biochemical and Biophysical Research Communications, vol. 321, no. 1, pp. 161-167, 2004.

[183] E. Giovannucci, "Nutrition, insulin, insulin-like growth factors and cancer," Hormone and Metabolic Research, vol. 35, no. 11-12, pp. 694-704, 2003.

[184] M. Pollak, "Insulin and insulin-like growth factor signalling in neoplasia," Nature Reviews Cancer, vol. 8, no. 12, pp. 915928, 2008.

[185] M. N. Pollak, E. S. Schernhammer, and S. E. Hankinson, "Insulin-like growth factors and neoplasia," Nature Reviews Cancer, vol. 4, no. 7, pp. 505-518, 2004.

[186] A. Grimberg and P. Cohen, "Role of insulin-like growth factors and their binding proteins in growth control and carcinogenesis," Journal of Cellular Physiology, vol. 183, no. 1, pp. 1-9, 2000.
[187] B. Lecka-Czernik, C. Ackert-Bicknell, M. L. Adamo, et al., "Activation of peroxisome proliferator-activated receptor $\gamma$ $(\operatorname{PPAR} \gamma)$ by rosiglitazone suppresses components of the insulin-like growth factor regulatory system in vitro and in vivo," Endocrinology, vol. 148, no. 2, pp. 903-911, 2007.

[188] C. Freudlsperger, I. Moll, U. Schumacher, and A. Thies, "Anti-proliferative effect of peroxisome proliferator-activated receptor $\gamma$ agonists on human malignant melanoma cells in vitro," Anti-Cancer Drugs, vol. 17, no. 3, pp. 325-332, 2006.

[189] S. H. Belli, M. N. Graffigna, A. Oneto, P. Otero, L. Schurman, and O. A. Levalle, "Effect of rosiglitazone on insulin resistance, growth factors, and reproductive disturbances in women with polycystic ovary syndrome," Fertility and Sterility, vol. 81, no. 3, pp. 624-629, 2004.

[190] D. Seto-Young, M. Paliou, J. Schlosser, et al., "Direct thiazolidinedione action in the human ovary: insulin-independent and insulin-sensitizing effects on steroidogenesis and insulinlike growth factor binding protein-1 production," The Journal of Clinical Endocrinology \& Metabolism, vol. 90, no. 11, pp. 6099-6105, 2005.

[191] D. Seto-Young, D. Avtanski, M. Strizhevsky, et al., "Interactions among peroxisome proliferator activated receptor- $\gamma$, insulin signaling pathways, and steroidogenic acute regulatory protein in human ovarian cells," The Journal of Clinical Endocrinology \& Metabolism, vol. 92, no. 6, pp. 2232-2239, 2007.

[192] A. Hilding, K. Hall, J. Skogsberg, E. Ehrenborg, and M. S. Lewitt, "Troglitazone stimulates IGF-binding protein1 by a PPAR $\gamma$-independent mechanism," Biochemical and Biophysical Research Communications, vol. 303, no. 2, pp. 693-699, 2003.

[193] O. Gavrilova, M. Haluzik, K. Matsusue, et al., "Liver peroxisome proliferator-activated receptor $\gamma$ contributes to hepatic steatosis, triglyceride clearance, and regulation of body fat mass," The Journal of Biological Chemistry, vol. 278, no. 36, pp. 34268-34276, 2003.

[194] W. He, Y. Barak, A. Hevener, et al., "Adipose-specific peroxisome proliferator-activated receptor $\gamma$ knockout causes insulin resistance in fat and liver but not in muscle," Proceedings of the National Academy of Sciences of the United States of America, vol. 100, no. 26, pp. 15712-15717, 2003.

[195] A. L. Hevener, W. He, Y. Barak, et al., "Muscle-specific Pparg deletion causes insulin resistance," Nature Medicine, vol. 9, no. 12, pp. 1491-1497, 2003.

[196] J. P. Berger, "Role of PPAR $\gamma$, transcriptional cofactors, and adiponectin in the regulation of nutrient metabolism, adipogenesis and insulin action: view from the chair," International Journal of Obesity, vol. 29, supplement 1, pp. S3-S4, 2005.

[197] J. P. Berger, T. E. Akiyama, and P. T. Meinke, "PPARs: therapeutic targets for metabolic disease," Trends in Pharmacological Sciences, vol. 26, no. 5, pp. 244-251, 2005.

[198] A. Okuno, H. Tamemoto, K. Tobe, et al., "Troglitazone increases the number of small adipocytes without the change of white adipose tissue mass in obese Zucker rats," The Journal of Clinical Investigation, vol. 101, no. 6, pp. 13541361, 1998.

[199] C. E. Quinn, P. K. Hamilton, C. J. Lockhart, and G. E. McVeigh, "Thiazolidinediones: effects on insulin resistance and the cardiovascular system," British Journal of Pharmacology, vol. 153, no. 4, pp. 636-645, 2008.

[200] A. H. Berg, T. P. Combs, X. Du, M. Brownlee, and P. E. Scherer, "The adipocyte-secreted protein Acrp30 enhances hepatic insulin action," Nature Medicine, vol. 7, no. 8, pp. 947-953, 2001. 
[201] C. R. Bruce, V. A. Mertz, G. J. F. Heigenhauser, and D. J. Dyck, "The stimulatory effect of globular adiponectin on insulin-stimulated glucose uptake and fatty acid oxidation is impaired in skeletal muscle from obese subjects," Diabetes, vol. 54, no. 11, pp. 3154-3160, 2005.

[202] S. E. Kahn, S. M. Haffner, M. A. Heise, et al., "Glycemic durability of rosiglitazone, metformin, or glyburide monotherapy," The New England Journal of Medicine, vol. 355, no. 23, pp. 2427-2443, 2006.

[203] C. L. Ackert-Bicknell, K. R. Shockley, L. G. Horton, B. LeckaCzernik, G. A. Churchill, and C. J. Rosen, "Strain-specific effects of rosiglitazone on bone mass, body composition, and serum insulin-like growth factor-I," Endocrinology, vol. 150, no. 3, pp. 1330-1340, 2009.

[204] P. F. Bruning, J. M. G. Bonfrer, P. A. H. Van Noord, A. A. M. Hart, M. De Jong-Bakker, and W. J. Nooijen, "Insulin resistance and breast-cancer risk," International Journal of Cancer, vol. 52, no. 4, pp. 511-516, 1992.

[205] E. Giovannucci, "Insulin, insulin-like growth factors and colon cancer: a review of the evidence," Journal of Nutrition, vol. 131, no. 11, supplement, pp. 3109S-3120S, 2001.

[206] A. Lev-Ran, "Mitogenic factors accelerate later-age diseases: insulin as a paradigm," Mechanisms of Ageing and Development, vol. 102, no. 1, pp. 95-113, 1998.

[207] J. Ma, E. Giovannucci, M. Pollak, et al., "A prospective study of plasma C-peptide and colorectal cancer risk in men," Journal of the National Cancer Institute, vol. 96, no. 7, pp. 546-553, 2004.

[208] G. G. Chen, J. F. Y. Lee, S. H. Wang, U. P. F. Chan, P. C. Ip, and W. Y. Lau, "Apoptosis induced by activation of peroxisomeproliferator activated receptor-gamma is associated with Bcl2 and Nf- $\kappa \mathrm{B}$ in human colon cancer," Life Sciences, vol. 70, no. 22, pp. 2631-2646, 2002.

[209] J. A. Copland, L. A. Marlow, S. Kurakata, et al., "Novel high-affinity PPAR $\gamma$ agonist alone and in combination with paclitaxel inhibits human anaplastic thyroid carcinoma tumor growth via p21WAF1/CIP1," Oncogene, vol. 25, no. 16, pp. 2304-2317, 2006.

[210] G. D. Girnun, E. Naseri, S. B. Vafai, et al., "Synergy between PPAR $\gamma$ ligands and platinum-based drugs in cancer," Cancer Cell, vol. 11, no. 5, pp. 395-406, 2007.

[211] C. Hafner, A. Reichle, and T. Vogt, "New indications for established drugs: combined tumor-stroma-targeted cancer therapy with PPAR $\gamma$ agonists, COX-2 inhibitors, mTOR antagonists and metronomic chemotherapy," Current Cancer Drug Targets, vol. 5, no. 6, pp. 393-419, 2005.

[212] A. Mustafa and W. D. Kruger, "Suppression of tumor formation by a cyclooxygenase-2 inhibitor and a peroxisome proliferator-activated receptor $\gamma$ agonist in an in vivo mouse model of spontaneous breast cancer," Clinical Cancer Research, vol. 14, no. 15, pp. 4935-4942, 2008. 


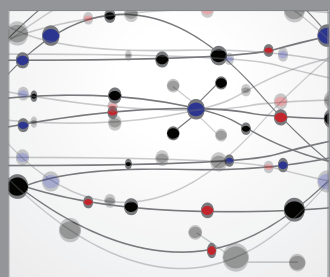

The Scientific World Journal
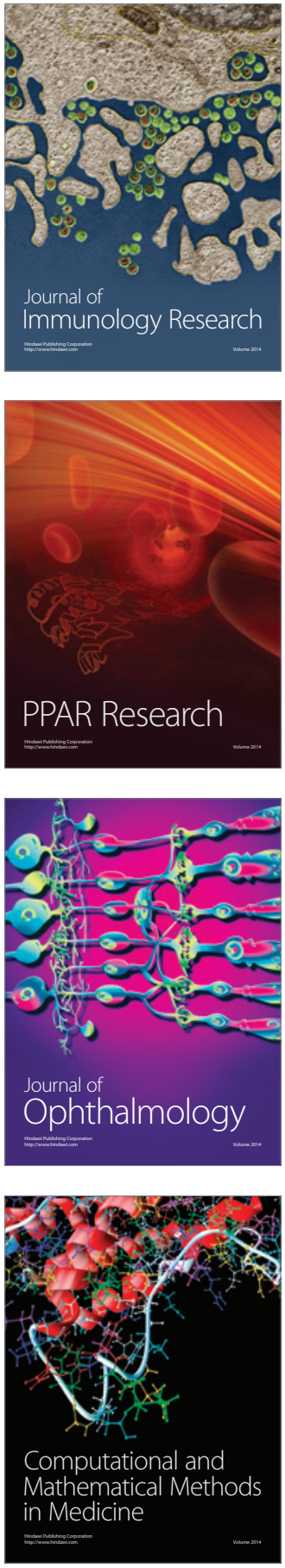

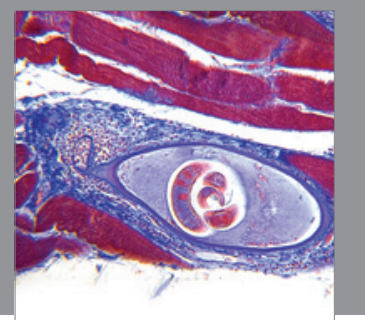

Gastroenterology

Research and Practice
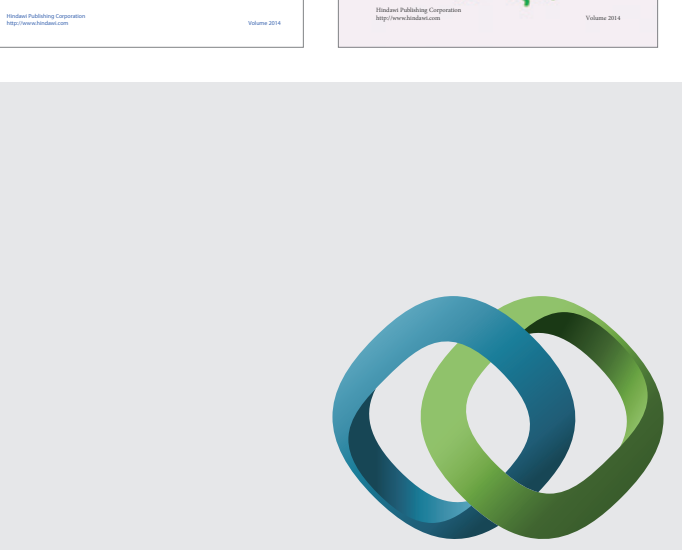

\section{Hindawi}

Submit your manuscripts at

http://www.hindawi.com
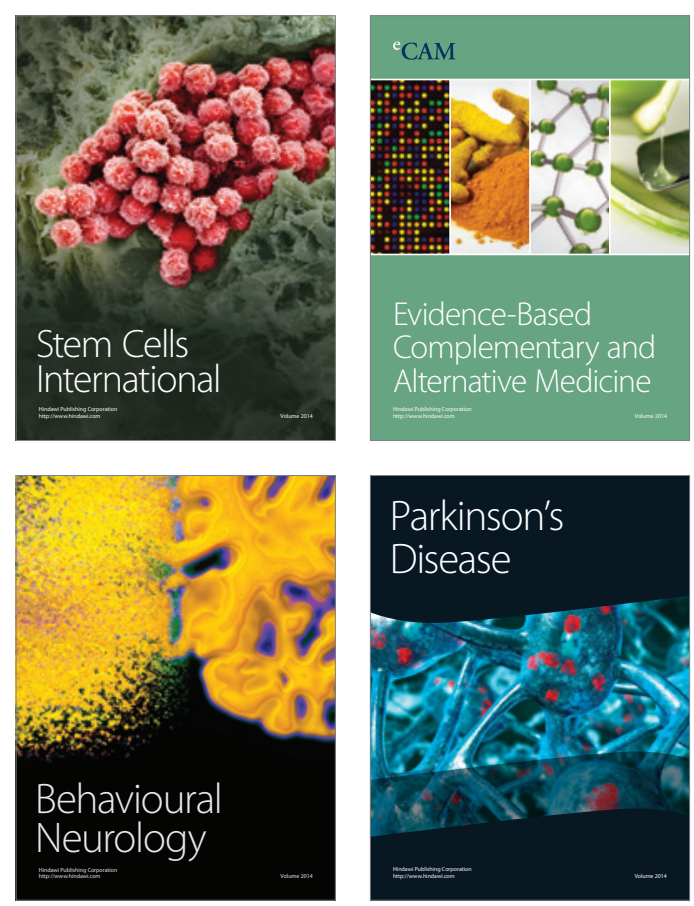

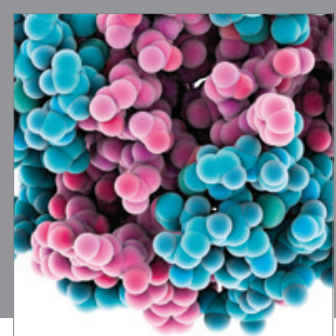

Journal of
Diabetes Research

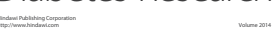

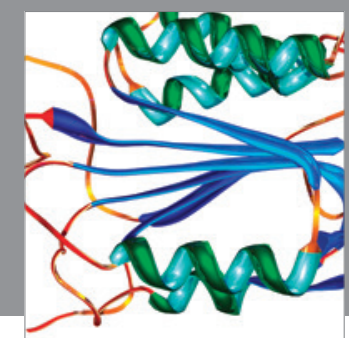

Disease Markers
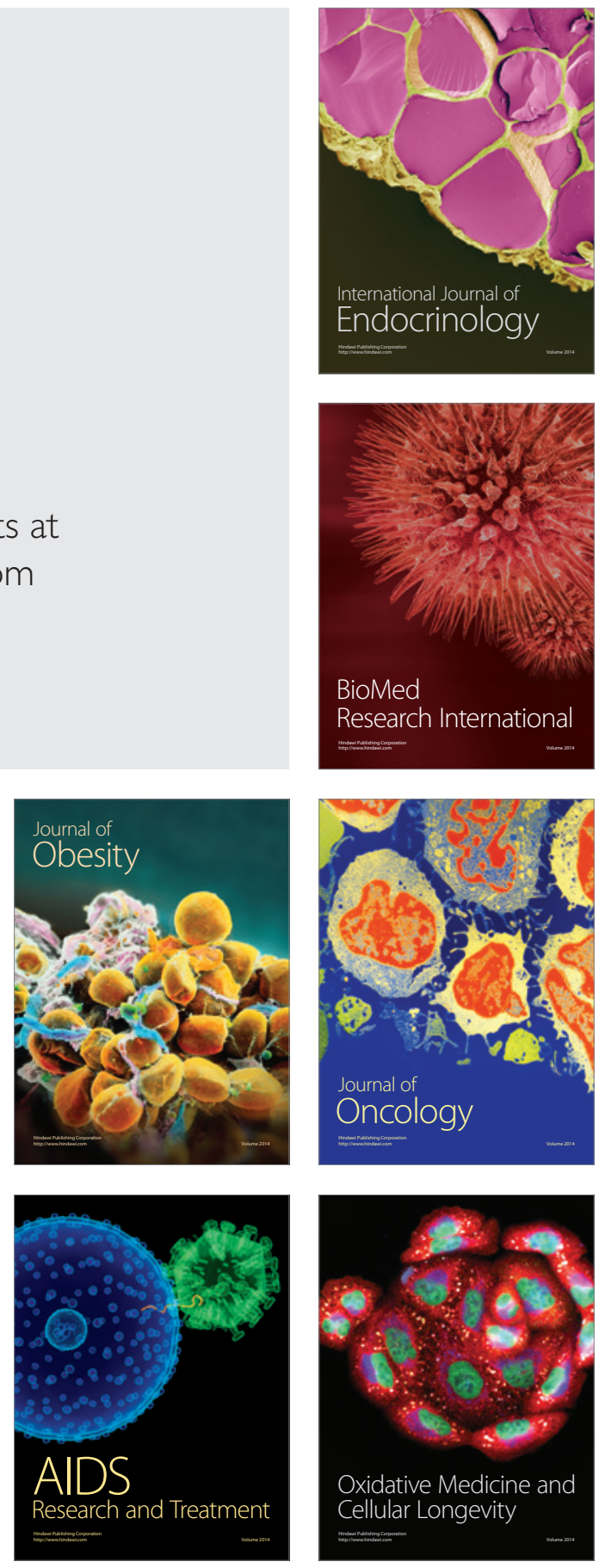